\title{
Research Progress on Photocatalytic/Photoelectrocatalytic Oxidation of Nitrogen Oxides
}

\author{
Shuangjun $\mathrm{Li}^{1} \cdot$ Linglong Chen ${ }^{1} \cdot$ Zhong Ma $^{1,2} \cdot$ Guisheng $\mathrm{Li}^{1,2} \cdot$ Dieqing Zhang ${ }^{1}$
}

Received: 31 March 2021 / Revised: 17 April 2021 / Accepted: 2 May 2021 / Published online: 31 May 2021

(c) The Author(s) 2021

\begin{abstract}
The emission of nitrogen oxides $\left(\mathrm{NO}_{x}\right)$ increases year by year, causing serious problems to our livelihoods. The photocatalytic oxidation of $\mathrm{NO}_{x}$ has attracted more attention recently because of its efficient removal of $\mathrm{NO}_{x}$, especially for low concentrations of $\mathrm{NO}_{x}$. In this review, the mechanism of the photocatalytic oxidation of $\mathrm{NO}_{x}$ is described. Then, the recent progress on the development of photocatalysts is reviewed according to the categories of inorganic semiconductors, bismuth-based compounds, nitrogen carbide polymer, and metal organic frameworks (MOFs). In addition, the photoelectrocatalytic oxidation of $\mathrm{NO}_{x}$, a method involving the application of an external voltage on the photocatalytic system to further increase the removal efficiency of $\mathrm{NO}_{x}$, and its progress are summarized. Finally, we outline the remaining challenges and provide our perspectives on the future directions for the photocatalytic oxidation of $\mathrm{NO}_{x}$.
\end{abstract}

Keywords $\mathrm{NO}_{x} \cdot$ Photocatalytic $\cdot$ Photoelectrocatalytic $\cdot$ Mechanism $\cdot$ Photocatalyst

\section{Introduction}

The livelihood of human beings, in terms of food, clothing, shelter, and transportation, has greatly improved since the beginning of the industrial revolution. However, the large consumption of fossil fuels, such as coal and petroleum, has led to the excessive emission of nitrogen oxides $\left(\mathrm{NO}_{x}\right)$ [1]. The $\mathrm{NO}_{x}$ emitted into the atmosphere not only causes acid rain [2, 3], photochemical smog [4, 5], PM2.5 $[6,7]$, and other environmental problems but also changes the climate and destroys the ozone layer [8]. In addition, $\mathrm{NO}_{x}$ severely damages the human heart and lungs and further reduces the efficacy of the human immune system [9], making the human body susceptible to respiratory diseases,

Shuangjun Li and Linglong Chen contributed equally to this work.

Dieqing Zhang

dqzhang@shnu.edu.cn

1 Key Laboratory of Resource Chemistry of Ministry of Education, Shanghai Key Laboratory of Rare Earth Functional Materials, Joint International Research Laboratory of Resource Chemistry, Ministry of Education, Shanghai Normal University, Shanghai 200234, China

2 School of Environmental and Geographical Sciences, Wetland Ecosystem Observation and Research Field Station, Shanghai Normal University, Shanghai 200234, China such as cough, eye inflammation, chest tightness, nausea, sore throat, and bronchitis [10,11]. Therefore, eliminating $\mathrm{NO}_{x}$ present in the atmosphere is important. Currently, the solutions to remove $\mathrm{NO}_{x}$ mainly are the typical adsorption method [12], nonselective catalytic reduction (NSCR) [13], and selective catalytic reduction (SCR) [14-16]. Most of these methods involve technologies for eliminating $\mathrm{NO}_{x}$ after its generation owing to many obstacles. The adsorption method is suitable only for the removal of a high concentration of $\mathrm{NO}_{x}$ in the combustion exhaust gas, has a high purification efficiency, and does not produce additional liquid wastes; however, it has a high operating cost [17]. Furthermore, NSCR or SCR technologies, in general, are limited to the treatment of high concentrations of $\mathrm{NO}_{x}[12$, 18], and their efficiency and economic benefits reduce for lower $\mathrm{NO}_{x}$ concentration. Therefore, the low concentration of $\mathrm{NO}_{x}$, especially in relatively closed places (such as urban streets, tunnels, underground parking lots, and various public indoors), cannot be effectively removed by these traditional methods [19]. The photocatalytic oxidation of $\mathrm{NO}_{x}$ is a green, low-cost method to eliminate $\mathrm{NO}_{x}$ (especially for low-concentration $\mathrm{NO}_{x}$ in the air at room temperature) that has attracted much attention recently [20,21]. Generally, the photocatalysts in this system absorb light energy and generate separated electrons and holes that further drive the oxidation of $\mathrm{NO}_{x}$ and play the most important role in the 
removal of $\mathrm{NO}_{x}$. Extensive efforts focused on developing highly active photocatalysts have resulted in a great amount of progress on photocatalysts for oxidation of $\mathrm{NO}_{x}$ in recent years. In this review, the mechanism of the photocatalytic oxidation of $\mathrm{NO}_{x}$ and the design principle of photocatalysts are described. The recent progress on the development of photocatalysts is then reviewed according to the categories of $\mathrm{TiO}_{2}$-based inorganic semiconductors, bismuth (Bi)-based inorganic semiconductors, graphite-phase carbon nitride and its complexes, and metal organic frameworks (MOFs). In addition, the progress on the development of photoelectrocatalytic oxidation of $\mathrm{NO}_{x}$ is also summarized. We outline the remaining challenges and provide perspectives on future directions for developing photocatalytic oxidation of $\mathrm{NO}_{x}$.

\section{Mechanism of Photocatalytic Oxidation of $\mathrm{NO}_{x}$}

Under light irradiation, a photocatalyst absorbs a photon (packet of light energy), and its valence band electron is promoted to the conduction band with the hole remaining in the valence band, creating an electron-hole pair. The holes on the valence band $\left(\mathrm{h}^{+}\right)$can oxidize the adsorbed water into $\mathrm{OH}$, and the electrons on the conduction $\left(\mathrm{e}^{-}\right)$band possess the ability to reduce the adsorbed oxygen into superoxide radicals $\left(\cdot \mathrm{O}_{2}^{-}\right)$[22]; these active oxygen species participate in the oxidation of $\mathrm{NO}_{x}$ to produce $\mathrm{NO}_{3}{ }^{-}, \mathrm{NO}_{2}{ }^{-}$, and a small amount of $\mathrm{NO}_{2}$. The mechanism of photocatalytic oxidation of $\mathrm{NO}_{x}$ is depicted in Fig. 1, and its specific reaction pathway is described as follows as Eqs. (1-6):

Photocatalyst $+h v \rightarrow \mathrm{e}^{-}+\mathrm{h}^{+}$

$\mathrm{e}^{-}+\mathrm{O}_{2} \rightarrow \cdot \mathrm{O}_{2}^{-}$

$\mathrm{h}^{+}+\mathrm{OH}^{-} \rightarrow \cdot \mathrm{OH}$

$\mathrm{NO}+\cdot \mathrm{O}_{2} \rightarrow \mathrm{NO}_{3}^{-}$

$\cdot \mathrm{OH}+\mathrm{NO} \rightarrow \mathrm{HNO}_{2}$

$\mathrm{HNO}_{2}+\cdot \mathrm{HO} \rightarrow \mathrm{HNO}_{3}$

Based on the above mechanism, the effectiveness of photocatalytic oxidation of $\mathrm{NO}_{x}$ is mainly dominated by photocatalyst. Firstly, electron-hole pair generation in photocatalysts is the trigger for the oxidation of $\mathrm{NO}_{x}$, and this generation mainly depends on whether the band gap of the photocatalyst matches the wavelength of the absorbed light. For example, $\mathrm{TiO}_{2}$ with a band gap of only $3.2 \mathrm{eV}$ can be excited to produce electron-hole pairs under the UV-light irradiation with a wavelength less than $380 \mathrm{~nm}$. However, UV light only accounts for $3 \%-5 \%$ of sunlight, whereas the proportion of visible light in sunlight can reach up to $43 \%$. To use visible light, new photocatalysts with a small band

Fig. 1 Mechanism of photocatalytic oxidation of $\mathrm{NO}_{x}($ Reproduced with permission from Ref. [22]. Copyright 2016 Elsevier)

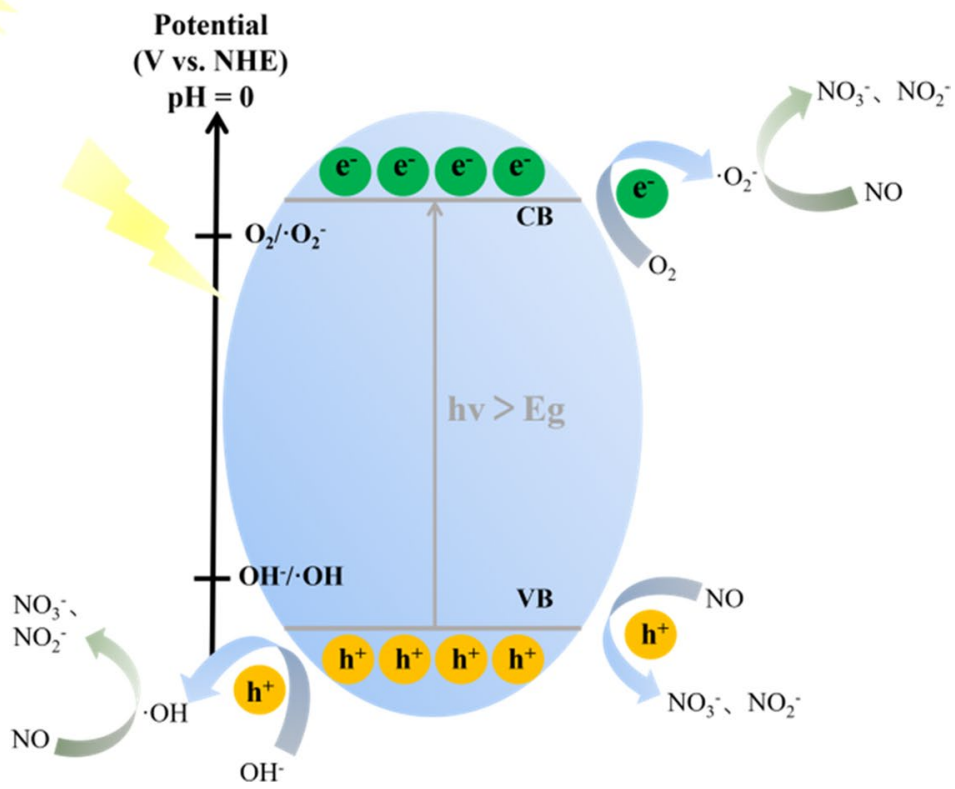


gap should be developed. Further, the lifetime of photogenerated electrons and holes also affects the efficiency of NO conversion. For example, the photogenerated holes only have a lifetime of $10^{-9} \mathrm{~s}$; this short lifetime severely decreased the occurrence of reaction between these active species and $\mathrm{NO}_{x}$. In addition, the charge transfer rate of a photocatalyst is also critical. Thus, extensive research has been focused on developing powerful photocatalysts by decreasing their band gaps and slowing down their recombination rates of electrons and holes.

\section{Recent Progress on Photocatalysts for Treating NO Gas}

Since 1994, when Ibusuki and Takeuchi [23] firstly applied photocatalytic technology to the removal of $\mathrm{NO}_{x}$, extensive attention has been devoted to this field, with several photocatalysts developed and evaluated toward oxidizing $\mathrm{NO}_{x}$. Currently, the reported photocatalysts could be classified mainly into four categories: (1) $\mathrm{TiO}_{2}$-based inorganic semiconductors [24-26], (2) Bi-based inorganic semiconductors [27, 28], (3) graphite-phase carbon nitride and its complexes [29], and (4) MOFs [30] (Fig. 2); recent progress in the development of these photocatalysts is summarized in the following section (Table 1).

\section{$\mathrm{TiO}_{2}$-Based Semiconductors}

Titanium oxide $\left(\mathrm{TiO}_{2}\right)$, a white, odorless, nontoxic powder, is a representative candidate of an inorganic semiconductor photocatalyst; $\mathrm{TiO}_{2}$ possesses three types of crystal structures: anatase, rutile, and brookite [20]. $\mathrm{TiO}_{2}$ is mainly divided into anatase and rutile phases [24]. Anatase $\mathrm{TiO}_{2}$ has a wide band gap (3.2 eV), which can be excited only by UV light, resulting in a very low utilization of sunlight. Furthermore, the high recombination probability of photogenerated carriers for $\mathrm{TiO}_{2}$ is not conducive to its wide application in the field of photocatalysis (PC). A study has found that the mixed crystals of anatase and rutile presented excellent photocatalytic activity because of the internal electric field formed between the two types that facilitated the separation of electrons and holes [25]. Gong and Selloni [31] revealed that the (001) facet of anatase has much higher activity than the (101) facet by theoretical calculations because the defect caused by the unsaturated coordination of $\mathrm{Ti}$ atoms on the (001) facet can increase the energy of the crystal surface. Subsequently, some experimental results have verified this
Fig. 2 Classification of photocatalysts toward the oxidation of $\mathrm{NO}_{x}$

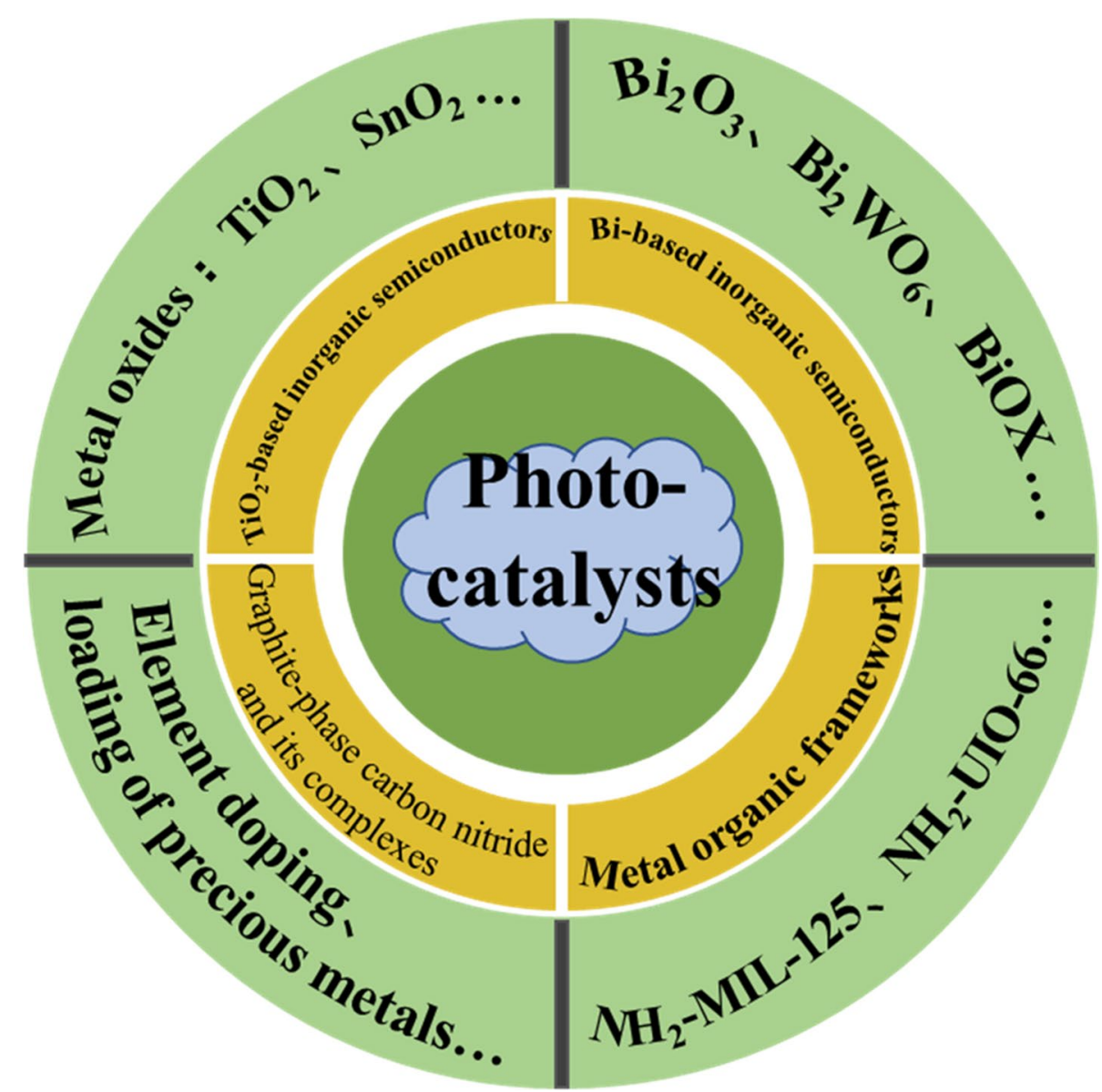


Table 1 Reported photocatalysts for the oxidation of $\mathrm{NO}_{x}$

\begin{tabular}{|c|c|c|c|c|c|}
\hline No & Photocatalysts & Light types & $\eta(\mathrm{NO})(\%)$ & Active species & Ref \\
\hline 1 & $\mathrm{Ag} \mathrm{NCs} / \mathrm{TiO}_{2}$ & Visible light & 63 & $\cdot \mathrm{O}_{2}^{-}, \mathrm{h}^{+}$ & [39] \\
\hline 2 & Blue $\mathrm{Fe}-\mathrm{TiO}_{2}$ & Simulated sunlight & 69 & $\cdot \mathrm{O}_{2}^{-}, \mathrm{h}^{+}, \mathrm{OH}$ & [40] \\
\hline 3 & $\mathrm{SnO}_{2} / \mathrm{TNTs}$ & Visible light & 59 & $\cdot \mathrm{O}_{2}^{-}, \cdot \mathrm{OH}$ & {$[26]$} \\
\hline 4 & $\mathrm{CNTs}_{-} \mathrm{TiO}_{2}$ & UV light & 86 & $\cdot \mathrm{O}_{2}^{-}, \mathrm{h}^{+}$ & [41] \\
\hline 5 & $\mathrm{Ni}-\mathrm{Bi}_{2} \mathrm{O}_{3}-5$ & Simulated sunlight & 52 & $\cdot \mathrm{OH}, \cdot \mathrm{O}_{2}^{-}$ & {$[28]$} \\
\hline 6 & $12 \% \mathrm{BP} / \mathrm{MBWO}$ & Visible light & 67 & $\cdot \mathrm{O}_{2}^{-}, \mathrm{h}^{+}, \cdot \mathrm{OH}$ & [46] \\
\hline 7 & $\mathrm{BiOCl}-\mathrm{OVs}$ & Simulated sunlight & 38 & $\cdot \mathrm{O}_{2}^{-}, \cdot \mathrm{OH}$ & {$[52]$} \\
\hline 8 & Bi-HBPO-102 & Visible light & 51 & $\cdot \mathrm{O}_{2}^{-}, \mathrm{h}^{+}, \mathrm{OH}$ & [59] \\
\hline 9 & $\mathrm{Bi} / \mathrm{Bi}_{2} \mathrm{O}_{2-x} \mathrm{CO}_{3}$ & Visible light & 51 & $\mathrm{~h}^{+}, \cdot \mathrm{OH}, \mathrm{H}_{2} \mathrm{O}_{2}$ & {$[61]$} \\
\hline 10 & Sr-doped g- $\mathrm{C}_{3} \mathrm{~N}_{4}$ & Visible light (300 W Xe lamp) & 55 & $\cdot \mathrm{O}_{2}^{-}, \cdot \mathrm{OH}$ & [69] \\
\hline 11 & $\mathrm{PdCl}_{2} / \mathrm{mgp}-\mathrm{CN}$ & $30 \mathrm{~W} \operatorname{LED}(\lambda \geq 420 \mathrm{~nm})$ & 66 & $\cdot \mathrm{O}_{2}^{-}, \cdot \mathrm{h}^{+}$ & {$[70]$} \\
\hline 12 & $\mathrm{~g}-\mathrm{C}_{3} \mathrm{~N}_{4} / \mathrm{MS}$ & A $150 \mathrm{~W}$ metal halide lamp $(\lambda \geq 420 \mathrm{~nm})$ & 79 & $\cdot \mathrm{O}_{2}^{-}, \mathrm{h}^{+}, \mathrm{OH}$ & [71] \\
\hline 13 & $\mathrm{~N}_{2 \mathrm{c}}$-deficient $\mathrm{g}-\mathrm{C}_{3} \mathrm{~N}_{4}$ & $300 \mathrm{~W}$ Xe lamp $(\lambda \geq 420 \mathrm{~nm})$ & 33 & $\cdot \mathrm{O}_{2}^{-}$ & {$[72]$} \\
\hline 14 & $\mathrm{~g}-\mathrm{C}_{3} \mathrm{~N}_{4} / \mathrm{Bi}_{4} \mathrm{O}_{5} \mathrm{I}_{2}$ & Tungsten halogen lamp $(\lambda \geq 420 \mathrm{~nm})$ & 51 & $\cdot \mathrm{O}_{2}^{-}, \cdot \mathrm{h}^{+}$ & [76] \\
\hline 15 & $\mathrm{Ag} @ \mathrm{NH}_{2}-\mathrm{MOP}(\mathrm{Ti})$ & Tungsten halogen lamps $(\lambda \geq 420 \mathrm{~nm})$ & 53 & $\cdot \mathrm{O}_{2}^{-}, \cdot \mathrm{OH}$ & {$[30]$} \\
\hline 16 & $\mathrm{GO} / \mathrm{NH}_{2}-\mathrm{MIL}-125$ & Tungsten halogen lamps $(\lambda \geq 420 \mathrm{~nm})$ & 65 & $\cdot \mathrm{OH}, \cdot \mathrm{O}_{2}^{-}$ & [87] \\
\hline 17 & $\mathrm{Cu}-\mathrm{NU} 7$ & $150 \mathrm{~W}$ tungsten lamps $(\lambda \geq 420 \mathrm{~nm})$ & 88 & $\cdot \mathrm{O}_{2}^{-}, \mathrm{h}^{+}$ & {$[88]$} \\
\hline 18 & $\mathrm{TiO}_{2}-\mathrm{CNT} / \mathrm{SSMs}$ & UV light & 60 & $\mathrm{~h}^{+}, \cdot \mathrm{OH}$ & {$[92]$} \\
\hline 19 & $\mathrm{TiO}_{2}$ nanorod array/FTO & UV light & 81 & $\mathrm{~h}^{+}, \cdot \mathrm{OH}$ & {$[100]$} \\
\hline
\end{tabular}

viewpoint [32-34]. However, the surface of the (001) facet requires special means to be stable because it has higher surface energy [35]. For instance, Yang et al. [34] found that the fluorine atom can significantly reduce the energy of the surface (001), making it even more stable than the surface (101). As a result, they made a breakthrough in using fluorine atom as the capping agent to synthesize micronsize $\mathrm{TiO}_{2}$ single crystals with (001) facet as the main crystal [36-38]. Han et al. [37] synthesized a rectangular $\mathrm{TiO}_{2}$ nanosheet with highly reactive (001) top and bottom surfaces using a simple hydrothermal approach with the aid of hydrofluoric acid solution. Owing to the exposure of a high percentage of (001) facets, this $\mathrm{TiO}_{2}$ nanosheet exhibited excellent photocatalytic efficiency that far exceeds that of the commercial P25. In addition, Chen et al. [38] used a solvothermal method to construct a (001) facet exposed $\mathrm{TiO}_{2}$ and porous graphene composite; this highly active (001) surface and excellent interface interaction in these unique three-dimensional (3D) structures provided a significant high-efficiency photocatalytic activity because of the effective molecular oxygen activation along with rapid in-plane and vertical light-induced charge transfer. Moreover, precious metal deposition, metal ion doping, and constructing semiconductor mixtures have also been used to modify $\mathrm{TiO}_{2}$ to improve its photocatalytic activity. Duan et al. [39] prepared $\mathrm{Ag} \mathrm{NCs} / \mathrm{TiO}_{2}$ composites by depositing $\mathrm{Ag}$ nanoclusters (NCs) onto $\mathrm{TiO}_{2}$ nanoparticles. The electrons generated from lowest unoccupied molecular orbital (LUMO) of Ag NCs migrated to the conduction band of $\mathrm{TiO}_{2}$ and induced the production of superoxide radicals that can efficiently oxidize NO (Fig. 3a) under visible light irradiation. The photocatalytic activity toward $\mathrm{NO}$ oxidation is three and two times that of pure $\mathrm{TiO}_{2}$ and $\mathrm{Ag} \mathrm{NC}$, respectively (Fig. 3b).

Furthermore, the work of Duan et al. effectively inhibited the formation of toxic byproduct, $\mathrm{NO}_{2}$, and exhibited excellent stability [39]. Using the metal-ion doping method, Martinez-Oviedo et al. [40] synthesized Fe- or $\mathrm{Cu}$-doped reduced blue $\mathrm{TiO}_{2}$ using $\mathrm{Li}$ in the ethylene-diamine (EDA) process. The photocatalyst with the incorporation of Fe showed the best photocatalytic performance among these doped photocatalysts because of the reduced band gap (Fig. 3c, d), increased visible-light absorption capability, the existence of oxygen vacancies/ $/ i^{3+}$ species, and efficient separation efficiency of photogenerated carriers. The structured $\mathrm{SnO}_{2} /$ $\mathrm{TiO}_{2}$ photocatalysts were fabricated by loading $\mathrm{SnO}_{2}$ nanoparticles onto $\mathrm{TiO}_{2}$ nanotubes (TNT) with the formation of $\mathrm{SnO}_{2}$ /TNTs heterojunctions through a one-step hydrothermal method [26]. As shown in Fig. 3e, the electrons generated in each TNT migrated to the conduction band of $\mathrm{SnO}_{2}$, whereas the holes in $\mathrm{SnO}_{2}$ valence band migrated to the valence band of TNTs. In that case, the recombination rate of photogenerated electron-hole pairs was effectively reduced, allowing the photocatalytic oxidation efficiency of $\mathrm{NO}$ to reach up to $60 \%$. Moreover, the production of $\mathrm{NO}_{2}$ was inhibited in this photocatalysis. Apart from the above methods, Zhang et al. [41] developed a general microwave antenna strategy to synthesize the discontinuous distribution of nano-semiconductors through carbon nanotubes (CNTs) 
(a)

(c)
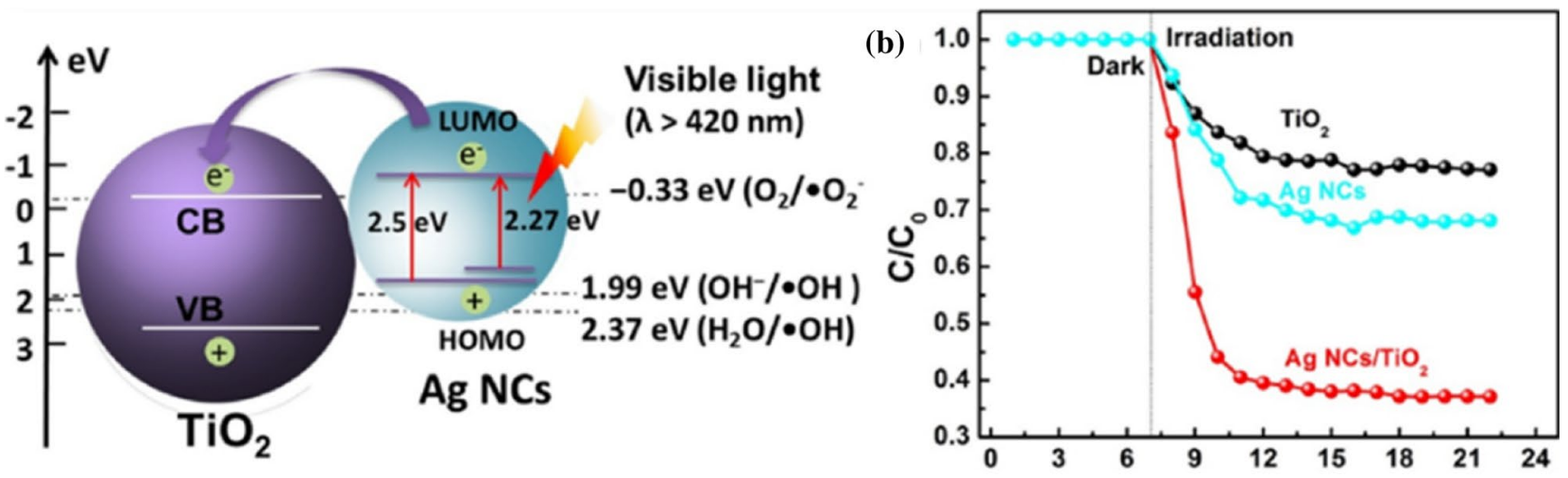

Time (min)

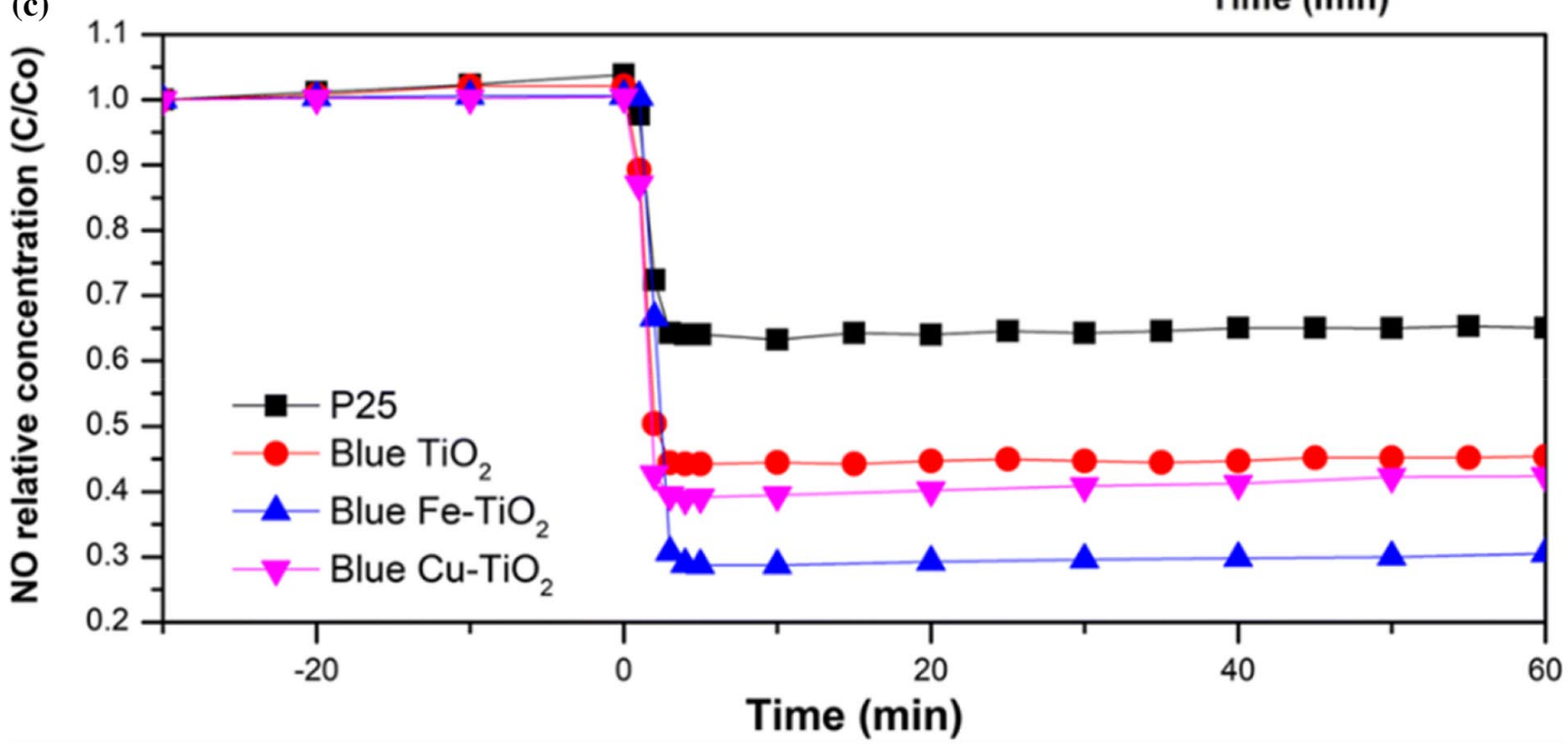

(d) i) ${\mathrm{Blue} \mathrm{TiO}_{2}}$

ii) Blue $\mathrm{Cu}-\mathrm{TiO}_{2}$

iii) Blue $\mathrm{Fe}-\mathrm{TiO}_{2}$
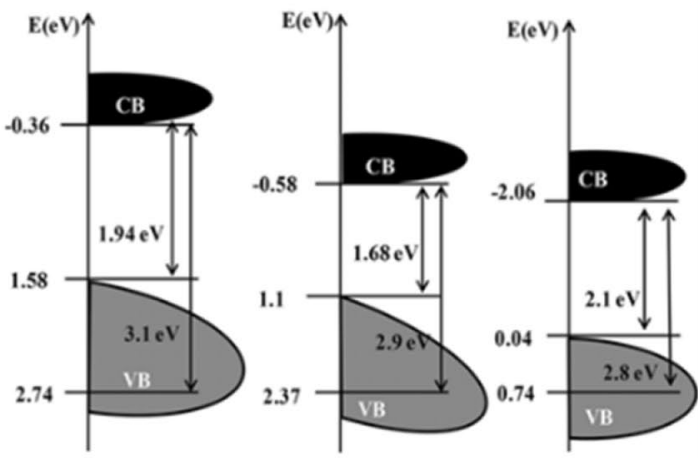

(e)

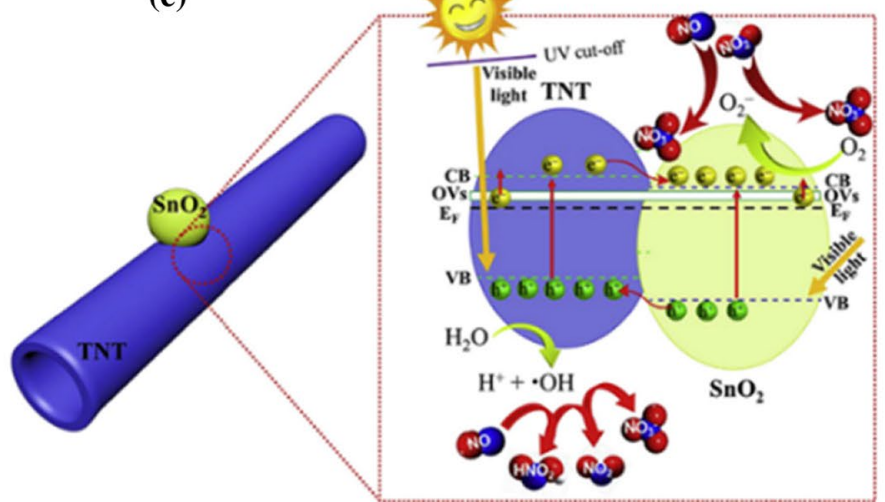

Fig. 3 a Electron transfer pathway of $\mathrm{Ag} \mathrm{NCs}$ modified $\mathrm{TiO}_{2}$; b $\mathrm{NO}$ oxidation reaction profiles of $\mathrm{TiO}_{2}, \mathrm{Ag} \mathrm{NCs}$, and $\mathrm{Ag} \mathrm{NCs} / \mathrm{TiO}_{2}$ ( Reproduced with permission from Ref. [39]. Copyright 2018 Elsevier); $\mathbf{c}$ the calculated band edges of blue $\mathrm{TiO}_{2}$, blue $\mathrm{Cu}-\mathrm{TiO}_{2}$, and blue $\mathrm{Fe}-\mathrm{TiO}_{2}$; $\mathbf{d}$ the enhancement of $\mathrm{NO}_{x}$ photo-oxidation by $\mathrm{Fe}$ - and
Cu-doped blue $\mathrm{TiO}_{2}$ (Reproduced with permission from Ref. [40]. Copyright 2020 Springer-Verlag GmbH Germany); e the structure and photocatalytic mechanism of $\mathrm{SnO}_{2}$ /TNT (Reproduced with permission from Ref. [26]. Copyright 2018 Elsevier)

CNTs, $\mathrm{TiO}_{2}$ microspheres, and the $3 \mathrm{D}$ CNTs conductive networks. For such a catalyst, a close "linear-contact" between CNTs and $\mathrm{TiO}_{2}$ was built through the covalent bonds of CNTs in this hybrid catalyst provided an efficient dual electron transfer pathway, i.e., the intimate "line-contact" among 

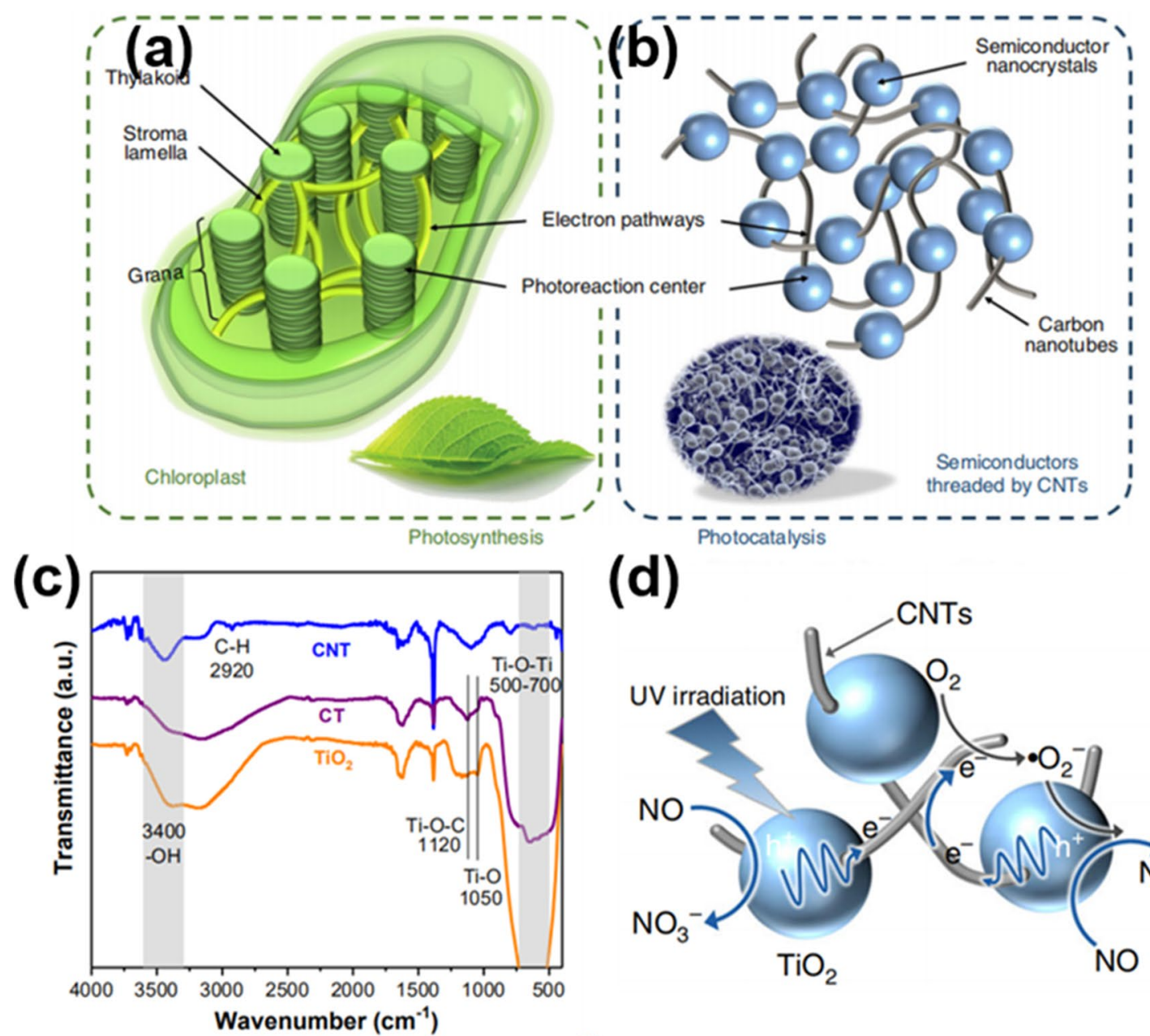

(d)
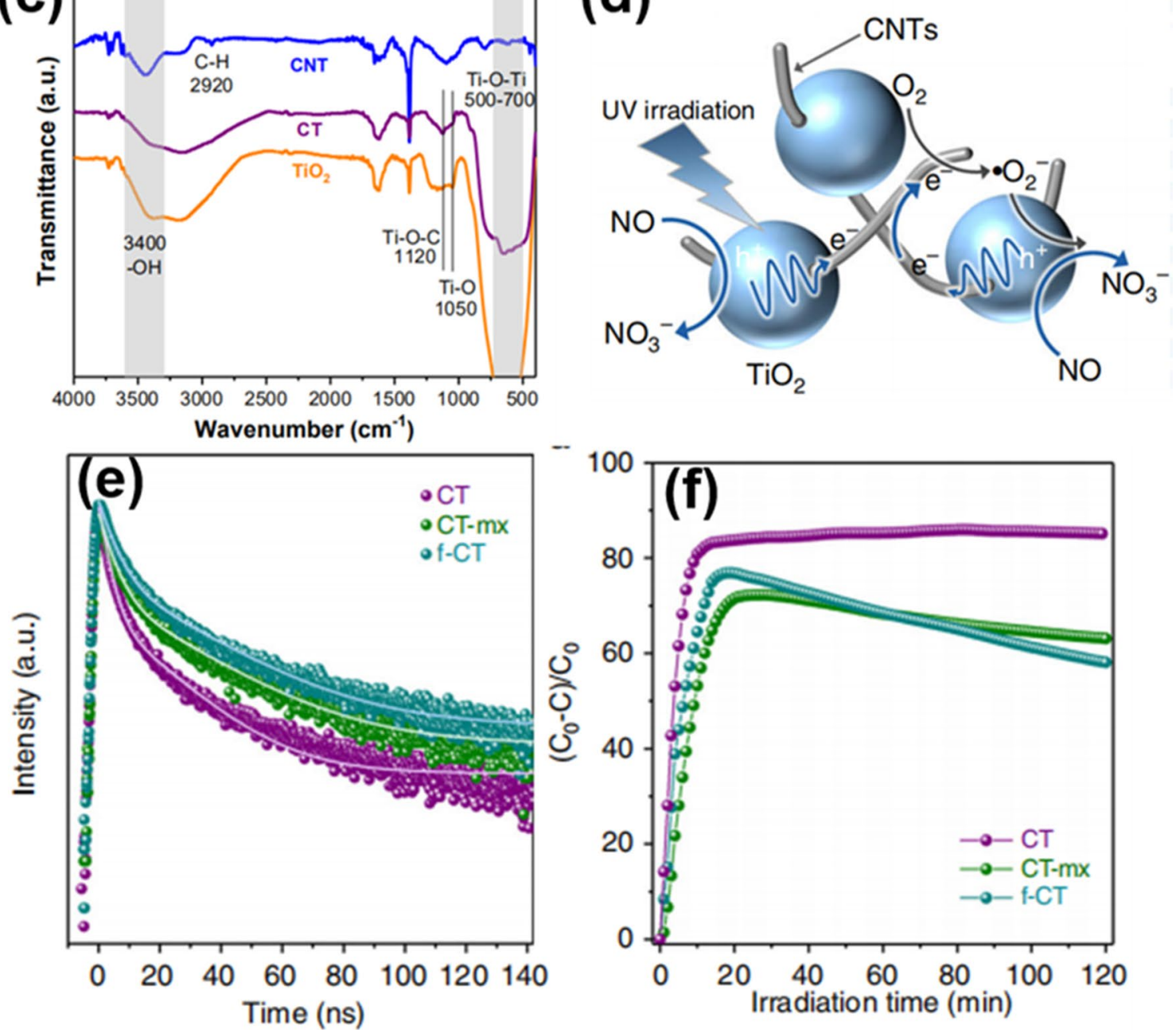

Fig. 4 a Top view of the chloroplast structure; $\mathbf{b}$ discontinuous structure of the distributed semiconductors with carbon-nanotube threads; c FT-IR spectra of the sample CT, pure $\mathrm{TiO}_{2}$ and CNT; $\mathbf{d}$ the photosynthesis mechanism of the chloroplast (left) and the photocatalytic $\mathrm{NO}$ removal mechanism of the chloroplast structured $\mathrm{CNTs}^{-\mathrm{TiO}_{2}}$; e

time-resolved transient photoluminescence decay profiles of samples $\mathrm{CT}\left(\mathrm{CNTs} / \mathrm{TiO}_{2}\right)$, f-CT (the completely encapsulated core-shell struc-

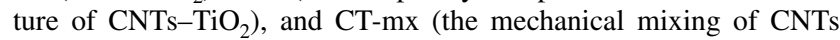
and $\mathrm{TiO}_{2}$ microspheres); f UV-light-driven photocatalytic $\mathrm{NO}$ oxidation performances ( Copyright 2019 The Author(s)) 
$\mathrm{Ti}-\mathrm{O}-\mathrm{C}=\mathrm{O}$ or $\mathrm{Ti}-\mathrm{O}-\mathrm{C}$ (located at $\sim 1120 \mathrm{~cm}^{-1}$ ) via the carboxyl/hydroxyl groups on the surface of CNTs and $\mathrm{TiO}_{2}$ during the synthesis process (Fig. 4c). As shown in Fig. 4d, this catalyst was excited by UV light to produce photongenerated carriers $\left(\mathrm{e}^{-}\right.$and $\left.\mathrm{h}^{+}\right)$in the $\mathrm{TiO}_{2}$ microspheres. The generated $\mathrm{e}^{-}$and $\mathrm{h}^{+}$can be further effectively separated through this linear-contact by transferring the electrons from $\mathrm{TiO}_{2}$ to a CNT. In that case, several accumulated electrons on the CNTs could react with $\mathrm{O}_{2}$ to form a high concentration of oxidant radicals $\left(\cdot \mathrm{O}_{2}^{-}\right)$that can react with NO. As shown in Fig. 4e, f, the CT sample was found to prolong the carrier life, with its NO conversion rate under UV irradiation being as high as $86 \%$ with good reaction stability.

\section{Bi-Based Inorganic Semiconductors}

Bi-based photocatalysts mainly include unary metal Bibased compounds, binary metal Bi-based compounds, bismuth oxyhalide compounds, bismuth phosphate, bismuth vanadate compounds, and bismuth oxycarbonate [27, 42, 43]. The monometallic Bi-based photocatalysts $\left(\mathrm{Bi}_{2} \mathrm{O}_{3}\right.$ and $\mathrm{Bi}_{2} \mathrm{~S}_{3}$ ) are the simplest Bi-based compounds, with the band gap ranging from 2.00 to $3.96 \mathrm{eV}$, which can be excited by visible light. Lei et al. [43] introduced oxygen vacancies into the $\beta-\mathrm{Bi}_{2} \mathrm{O}_{3}$ catalyst; after optimization, under visible light irradiation, the photocatalytic NO removal rate of defective $\beta-\mathrm{Bi}_{2} \mathrm{O}_{3}$ increased from $25.2 \%$ to $52.0 \%$. Dong et al. [28] prepared two types of Ni-doped $\mathrm{Bi}_{2} \mathrm{O}_{3}$ microsphere $\left(\mathrm{Ni}-\mathrm{Bi}_{2} \mathrm{O}_{3}-5\right.$ and $\left.\mathrm{Ni}-\mathrm{Bi}_{2} \mathrm{O}_{3}-2\right)$ photocatalysts through a one-pot solvothermal method (Fig. 5a-d); the two catalysts exhibited much higher photocatalytic activities, $52 \%$ and $35 \%$ for $\mathrm{Ni}-\mathrm{Bi}_{2} \mathrm{O}_{3}-5$ and $\mathrm{Ni}-\mathrm{Bi}_{2} \mathrm{O}_{3}-2$, respectively, compared to $31 \%$ for the pure $\mathrm{Bi}_{2} \mathrm{O}_{3}$ sample because the doped $\mathrm{Ni}$ changed the geometric and electronic structure. In addition, $\mathrm{Ni}-\mathrm{Bi}_{2} \mathrm{O}_{3}-5$ showed no obvious activity drop after five cycles (Fig. 5e, f).

Besides $\mathrm{Bi}_{2} \mathrm{O}_{3}, \mathrm{Bi}_{2} \mathrm{WO}_{6}$-based semiconductors have also been proven as effective photocatalysts for oxidizing $\mathrm{NO}_{x}$ owing to their special crystal structures $[44,45]$. However, the photocatalytic activity of traditional $3 \mathrm{D} \mathrm{Bi}_{2} \mathrm{WO}_{6}$ is not satisfactory because of the rapid recombination of electron-hole pairs, the narrow visible light response range, and the low specific surface area resulting in the low exposure of active sites. Hu et al. [46] prepared a Z-type heterojunction of $2 \mathrm{D} / 2 \mathrm{D}$ black phosphorus/single layer $\mathrm{Bi}_{2} \mathrm{WO}_{6}$ as a 2D nanosheet catalyst that exhibited high specific surface area (Fig. 6a, b), many active sites, and a unique electronic structure; this catalyst achieved $67 \%$ visible-light catalytic activity for removing NO and long-term stability (Fig. 6c, d).

Bismuth oxyhalide, as an important Bi-based semiconductor, possesses excellent optical properties owing to its layered structure consisting of a double layer of interlaced halogen atoms $\left[\mathrm{Bi}_{2} \mathrm{O}_{2}\right]^{2+}$. Recently, p-block bismuth oxyhalides ( $\mathrm{BiOX}, \mathrm{X}=\mathrm{Cl}, \mathrm{Br}$, I) have attracted widespread attention because of its unique polar two-dimensional (2D) layered crystal structure [47-51]. He et al. [42] designed a novel Bi quantum dot (QDS)-injected C-doped $\mathrm{BiOCl}$ photocatalyst $(\mathrm{C} / \mathrm{BOC} / \mathrm{B})$ that had a $\mathrm{NO}_{x}$ removal efficiency that reached the maximum value of $53.0 \%$ within $8 \mathrm{~min}$, with no significant attenuation observed after continuous irradiation, indicating the modification of Bi QDS can further improve the photocatalytic performance of the $\mathrm{C} / \mathrm{BOC}$ catalyst. Dong et al. [52] prepared $\mathrm{BiOCl}$ nanosheets with oxygen vacancies by reconstructing hydrophobic $\mathrm{BiOCl}$. Because oxygen vacancies possess electron trapping ability and promote the separation of light-excited charges, $\mathrm{BiOCl}$ nanosheets showed enhanced visible light absorption. For example, under simulated sunlight, the defective $\mathrm{BiOCl}$ exhibited a NO removal rate of $38 \%$, which is much higher than that of $\mathrm{BiOCl}(27 \%)$, attributed to the increased carrier density and charge separation performance. Under visible light ( $\geq 420 \mathrm{~nm}$ ), the defective $\mathrm{BiOCl}$ exhibited $11 \% \mathrm{NO}$ removal activity, whereas BiOCl only possessed a negligible NO removal rate. This work also revealed the correlation between atomic defects and photocatalytic performance and provided the inspiration for the design and manufacture of photocatalysts. Bismuth phosphate $\left(\mathrm{BiPO}_{4}\right)$ contains acid radical ions, with the oxygen located in the acid radical rather than the metal oxygen structure; this configuration can greatly promote the separation of photogenerated electrons and holes [53]. Thus, $\mathrm{BiPO}_{4}$ has been widely used for driving photocatalytic reactions. Generally, $\mathrm{BiPO}_{4}$ has two crystal structures, hexagonal and monorhombic; these crystal structures have different light absorption and charge transferability because of their distinguished surface atoms arrangements [54-57]. Furthermore, the plasmon resonance effect was combined with $\mathrm{BiPO}_{4}$ via loading metallic $\mathrm{Bi}$, which can be used as an electron donor [58, 59]. Dong et al. [59] observed that the deposition of Bi metal on the (102) facet of the defective hexagonal $\mathrm{BiPO}_{4}$ (Fig. 7a) resulted in a $51 \% \mathrm{NO}$ removal rate, much higher than that of the Bi metal decorated on the (120) facet of the defective monoclinic $\mathrm{BiPO}_{4}$ (36\%) (Fig. 7b). In addition, with the synergistic effect of the surface plasmon resonance effect and phosphoric acid defect, a new mechanism for electron transmission from $\left[\mathrm{Bi}_{2} \mathrm{O}_{2}\right]^{2+} \rightarrow \mathrm{Bi}$ metal $\rightarrow \mathrm{PO}_{4}{ }^{3-}$ was constructed on Bi-BiPO ${ }_{4}$ catalyst (Fig. $\left.7 \mathrm{c}\right) . \mathrm{B}(\mathrm{BiO})_{2} \mathrm{CO}_{3}$ belongs to the Oliviers-related oxide family, with a layered structure of $\mathrm{Bi}_{2} \mathrm{O}_{2}$ and $\mathrm{CO}_{3}{ }^{2-}$ layers interlaced with each other [22]. The interface between the $\left[\mathrm{Bi}_{2} \mathrm{O}_{2}\right]^{2+}$ and $\mathrm{CO}_{3}{ }^{2-}$ layer can promote the separation of light-induced electron-hole pairs, thereby improving its quantum efficiency; however, the production of $\mathrm{NO}_{2}$ was found to be typically present [60]. To address this problem, Huang et al. [61] synthesized $\mathrm{Bi} / \mathrm{Bi}_{2} \mathrm{O}_{2-x} \mathrm{CO}_{3}$ nanosheets with abundant oxygen 

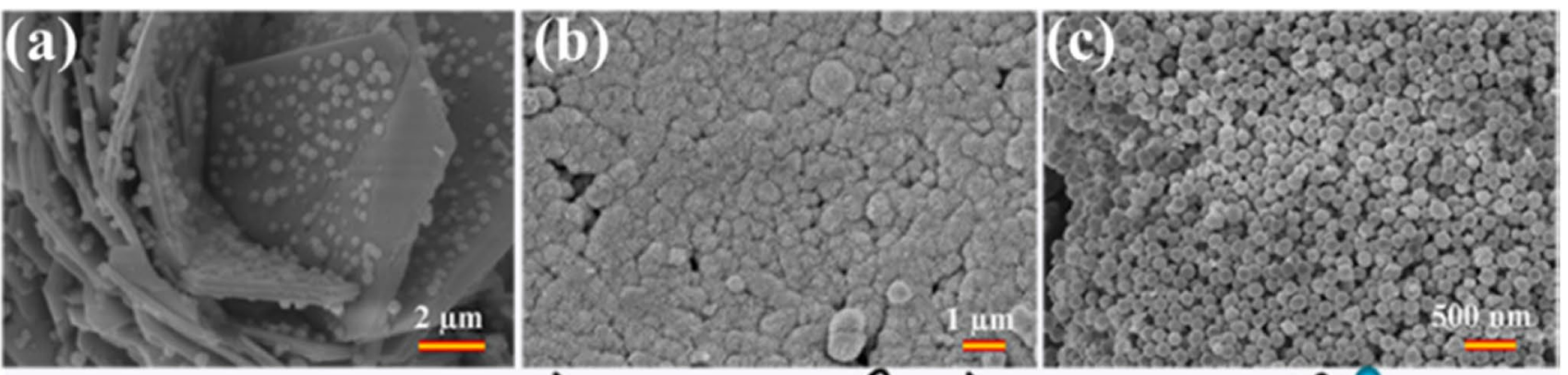

(d)
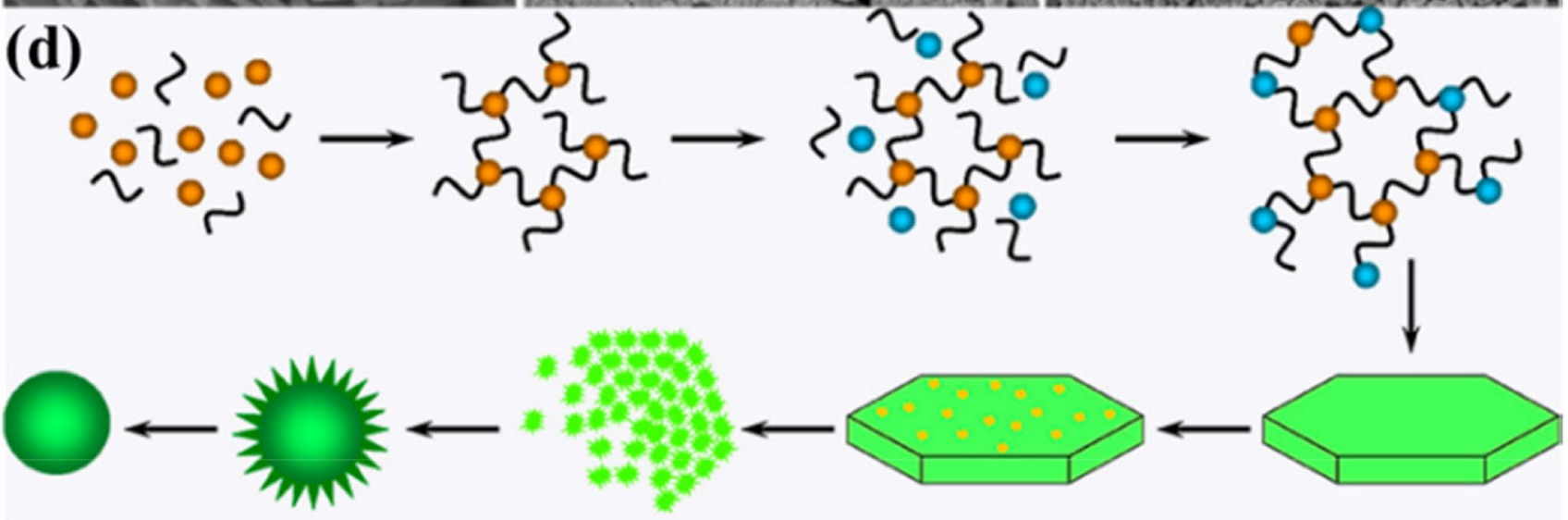

$\mathrm{Bi}^{3+}$

(e)

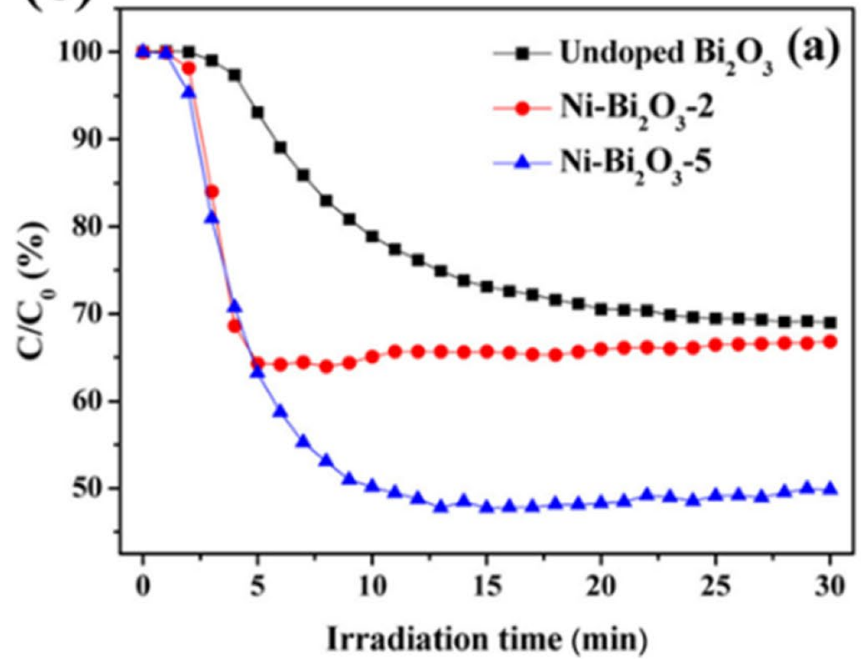

Fig. 5 SEM images of a undoped $\mathrm{Bi}_{2} \mathrm{O}_{3} ; \mathbf{b}$ Ni- $\mathrm{Bi}_{2} \mathrm{O}_{3}-2$, and $\mathbf{c} \mathrm{Ni}-$ $\mathrm{Bi}_{2} \mathrm{O}_{3}-5$; $\mathbf{d}$ schematic illustration of the proposed formation mechanism of $\mathrm{Ni}-\mathrm{Bi}_{2} \mathrm{O}_{3}$ microspheres; e photocatalytic performances of

vacancies on the surface. The removal rate of NO for these nanosheets under visible light was found to be as high as $51 \%$, and the selectivity for $\mathrm{NO}_{3}{ }^{-}$was found to reach up to $98 \%$ (Fig. 7d, e). With the Bi plasma resonance, hydrogen peroxide was generated through two electrons path on (f)

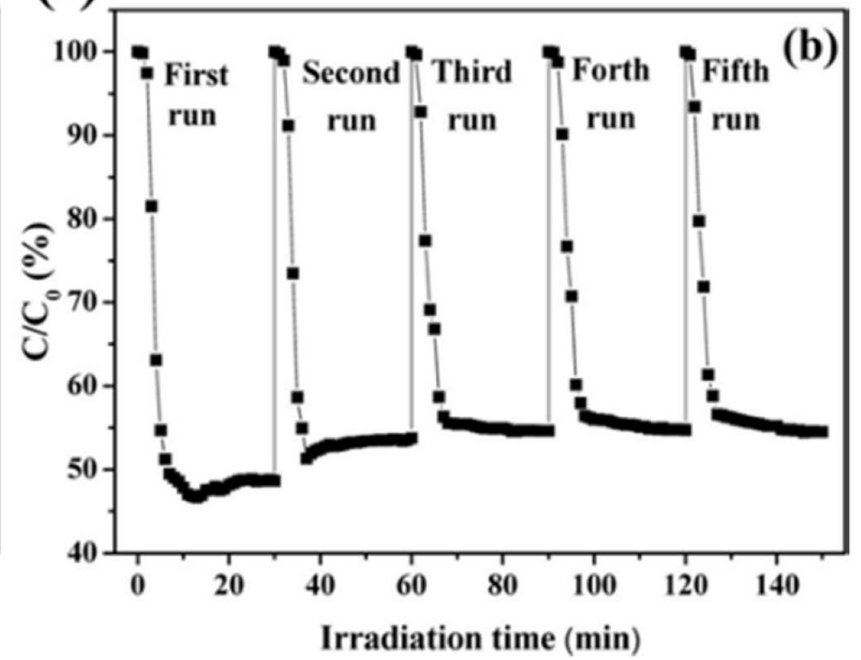

$\mathrm{Bi}_{2} \mathrm{O}_{3}, \mathrm{Ni}-\mathrm{Bi}_{2} \mathrm{O}_{3}-2$, and $\mathrm{Ni}-\mathrm{Bi}_{2} \mathrm{O}_{3}-5 ; \mathbf{f}$ multiple photocatalytic reaction over $\mathrm{Ni}-\mathrm{Bi}_{2} \mathrm{O}_{3}-5$ ( Reproduced with permission from Ref. [28]. Copyright 2017 American Chemical Society)

this catalyst; thus, the generation of $\mathrm{NO}_{2}$ was inhibited. Furthermore, the oxygen vacancies between the $\mathrm{Bi}-\mathrm{O}$ layers acted as an electron transfer channel between $\mathrm{Bi}$ and $\mathrm{Bi}_{2} \mathrm{O}_{2-x} \mathrm{CO}_{3}$, improving the separation rate of photogenerated carriers and thus, the photocatalytic efficiency. 

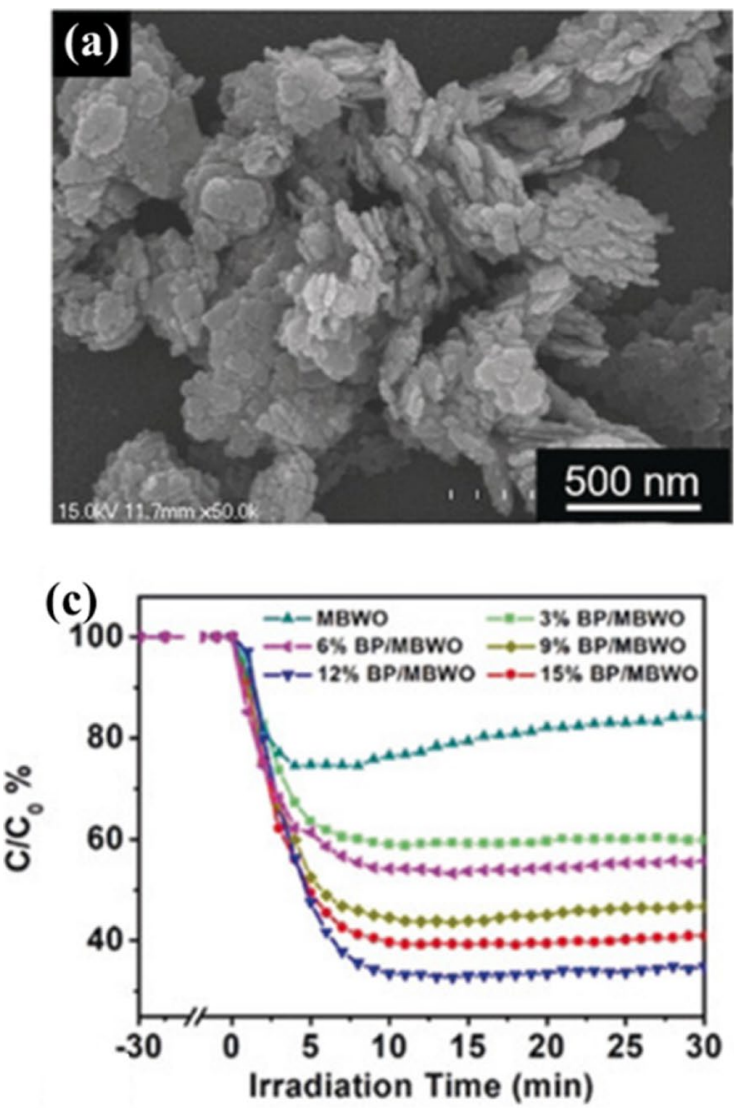

Fig. 6 SEM images of a MBWO (monolayer $\mathrm{Bi}_{2} \mathrm{WO}_{6}$ ) nanosheets; $\mathbf{b}$ $12 \% \mathrm{BP} / \mathrm{MBWO}$ (black phosphorus and monolayer $\mathrm{Bi}_{2} \mathrm{WO}_{6}$ ) heterojunctions; $\mathbf{c}$ the relevant photocatalytic NO removal rates; $\mathbf{d}$ multiple

\section{Graphite-Phase Carbon Nitride and Its Complex}

Graphite-phase carbon nitride $\left(\mathrm{g}-\mathrm{C}_{3} \mathrm{~N}_{4}\right)$ is a nonmetallic, polymer semiconductor photocatalytic catalyst that has many advantages, including small band gap width of $2.7 \mathrm{eV}$, visible light photocatalytic activity, low cost, good acid and alkali corrosion resistance, and excellent chemical and thermal stabilities [20, 29, 62-64]. However, the low separation efficiency of photogenerated electron-hole pairs and poor visible-light utilization efficiency of $\mathrm{g}-\mathrm{C}_{3} \mathrm{~N}_{4}$ limit its applications in PC [65]. Studies have revealed that the photocatalytic activity of $\mathrm{g}-\mathrm{C}_{3} \mathrm{~N}_{4}$ toward removing low-concentration $\mathrm{NO}_{x}$ can achieve very high efficiency through elemental doping [66], loading precious metals [67], or morphology tuning [68]. For example, Zhou et al. [69] modified $\mathrm{g}-\mathrm{C}_{3} \mathrm{~N}_{4}$ by $\mathrm{Sr}$ embedding, $\mathrm{Sr}$ replacing $\mathrm{N}$ atoms, and $\mathrm{Sr}$ filling holes; all these Sr-doped catalysts reduced the band gap of $\mathrm{g}-\mathrm{C}_{3} \mathrm{~N}_{4}$ and thus improved the NO removal efficiency under visible light, and effectively inhibited the production of $\mathrm{NO}_{2}$. More specifically, the multisite doping of $\mathrm{Sr}$ could improve the $\mathrm{NO}$ removal rate by 1.5 times while reducing the conversion rate of $\mathrm{NO}_{2}$
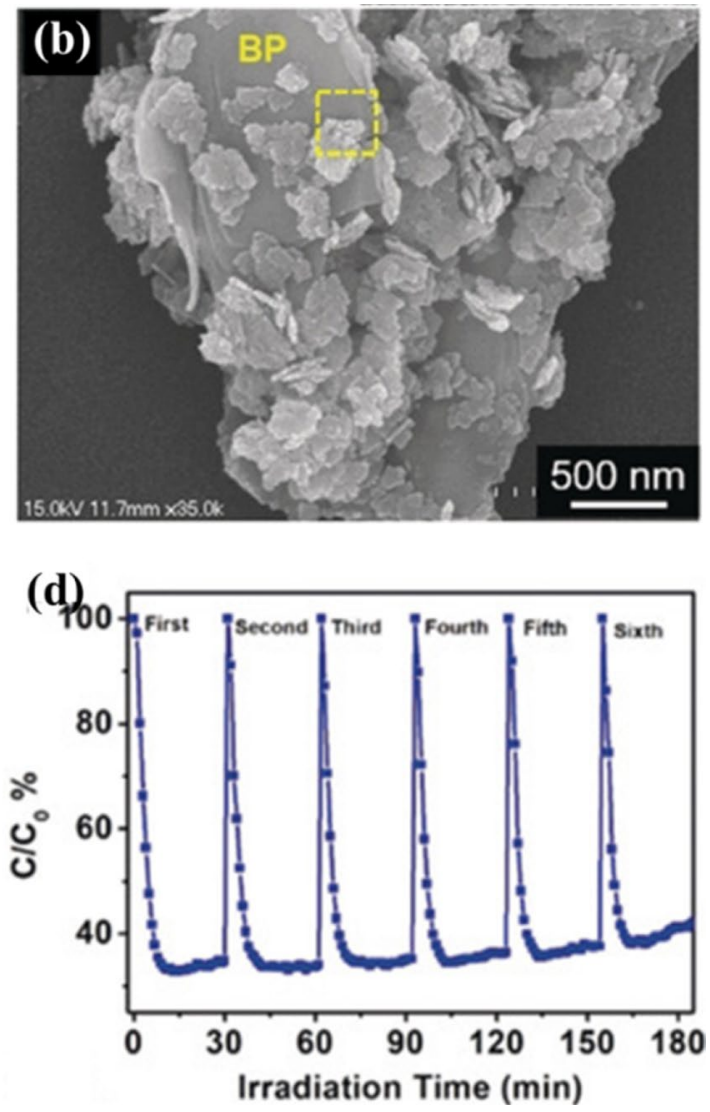

cycles of photocatalytic reactions over $12 \%$ BP/MBWO ( Reproduced with permission from Ref. [46]. Copyright 1999-2021 John Wiley \& Sons, Inc.)

from $63 \%$ to $16 \%$. Zhang et al. [70] developed a simple and efficient molecular/solid hybrid photocatalyst composed of noble metal (such as $\mathrm{Au}^{\mathrm{III}}, \mathrm{Pt}^{\mathrm{IV}}$, and $\mathrm{Pd}^{\mathrm{II}}$ ) chlorides, and mesoporous graphite carbon nitride (mpg-CN). Adding $\mathrm{PdCl}_{2}$ improved the photocatalytic ability of mpg-CN and increased the efficiency from $32 \%$ to $65 \%$ for the photocatalytic removal of $1000 \mathrm{ppb}$ of NO. Li et al. [64] reported a $\mathrm{C}_{3} \mathrm{~N}_{4}$ supported $\mathrm{Pd}$ nanoparticles catalyst ( $\mathrm{PdCN}$ ) for photocatalytic oxidation of $\mathrm{NO}_{x}$; this $\mathrm{PdCN}$ was found to have a better purification effect on NO in the air, reaching a maximum of $51.5 \%$ in the first $5 \mathrm{~min}$, followed by stabilization at $44.9 \%$. Yang et al. [71] successfully synthesized a $\mathrm{g} \mathrm{C}_{3} \mathrm{~N}_{4} /$ melamine sponge $\left(\mathrm{g}-\mathrm{C}_{3} \mathrm{~N}_{4} / \mathrm{MS}\right)$ using the ultrasonic coating method with $\mathrm{g}-\mathrm{C}_{3} \mathrm{~N}_{4}$ uniform dispersion and immobilization on the melamine skeleton (Fig. 8a-d). The $\mathrm{g}-\mathrm{C}_{3} \mathrm{~N}_{4} / \mathrm{MS}$ composite still possessed the porous structure of MS, and its specific surface area was much larger than that of the photocatalyst in powder form. In that case, $\mathrm{g}^{-} \mathrm{C}_{3} \mathrm{~N}_{4} / \mathrm{MS}$ exposed more active sites, enhanced visible light absorption, and enhanced separation of photogenerated carriers; the NO removal rate reached $79 \%$ in the first 5 min under visible-light irradiation, which was 


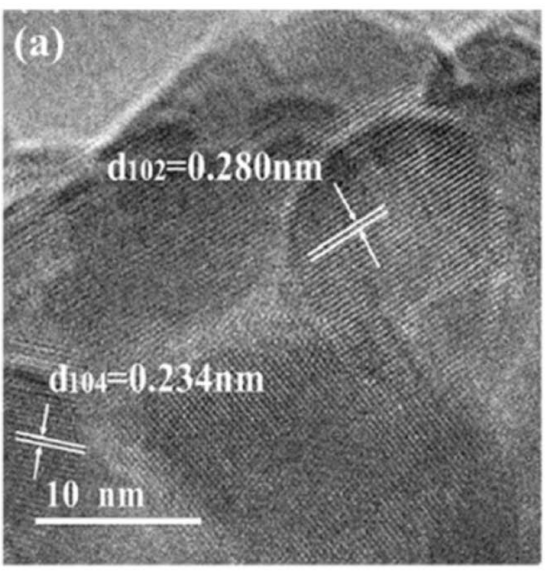

(d)

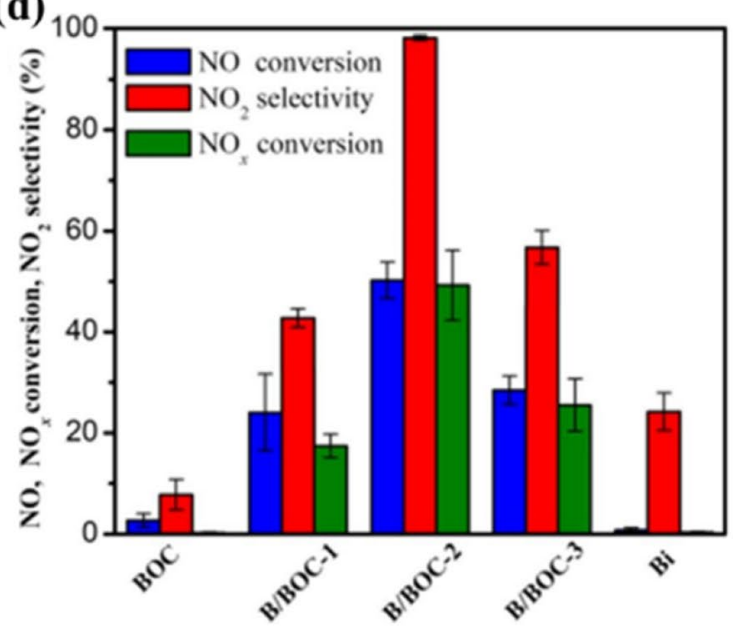

Fig. 7 a HRTEM image of Bi-HBPO-102; b HRTEM image of BiMBPO-120 ( Reproduced with permission from Ref. [59]. Copyright 2018 Elsevier); c proposed photocatalytic mechanism on Bi-HBPO-102 and Bi-MBPO-120; d photocatalytic NO removal effi-

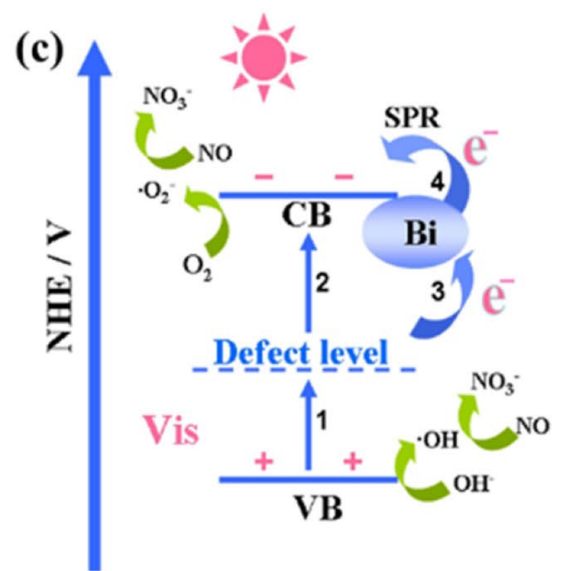

(e)

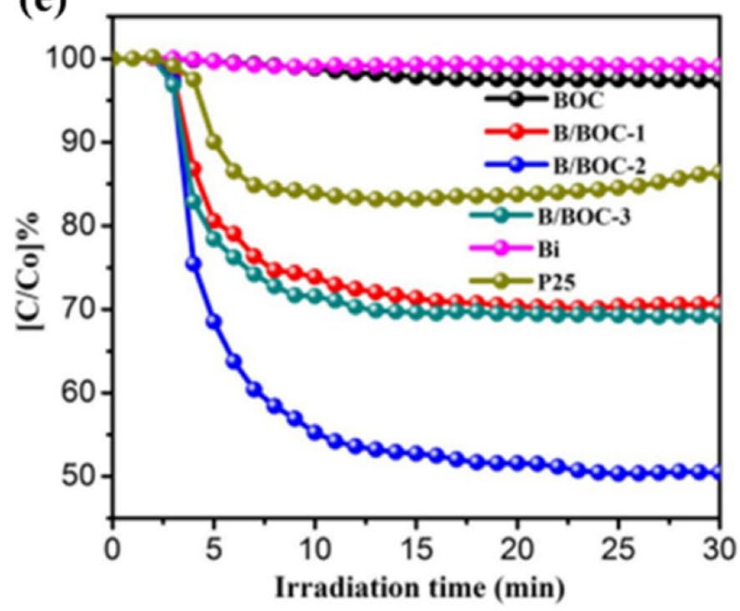

ciencies $\left(C / C_{0}\right)$ of as-prepared samples; e $\mathrm{NO}, \mathrm{NO}_{x}$ conversion and $\mathrm{NO}_{2}$ selectivity obtained for catalysts subjected to $30 \mathrm{~min}$ irradiation (Reproduced with permission from Ref. [61]. Copyright 2019 Elsevier)
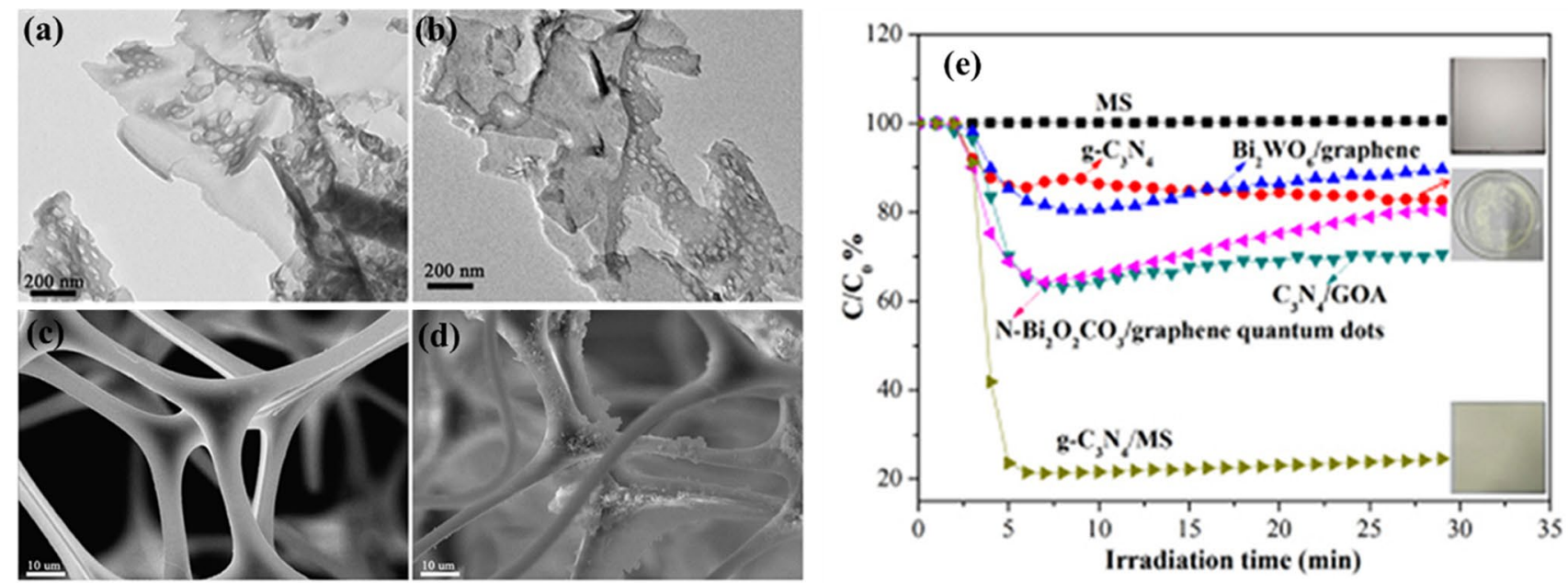

Fig. 8 TEM images of samples: a g- $\mathrm{C}_{3} \mathrm{~N}_{4}$; b sonicated g- $\mathrm{C}_{3} \mathrm{~N}_{4}$; SEM images of $\mathbf{c} \mathrm{MS}$ and $\mathbf{d}$ g- $\mathrm{C}_{3} \mathrm{~N}_{4} / \mathrm{MS}$; e NO removal ratios of various samples ( Reproduced with permission from Ref. [71]. Copyright 2018 The Author(s)) 
approximately 4.5 times that of the powder $\mathrm{g}-\mathrm{C}_{3} \mathrm{~N}_{4}(18 \%)$, whereas the original MS did not work for the removal of NO (Fig. 8e).

In addition, the photocatalytic activity of $\mathrm{g}_{-} \mathrm{C}_{3} \mathrm{~N}_{4}$ can be significantly improved by the introduction of defects [72]. Wang et al. [73] prepared $\mathrm{g}-\mathrm{C}_{3} \mathrm{~N}_{4}$ microtubes with adjustable $\mathrm{N}$ vacancy concentration using the in situ soft chemical method (Fig. 9a, b). They found the surface $\mathrm{N}$-vacancies not only acted as the specific sites for the adsorption, activation of the reactants, and photoinduced electron capture but also enhanced the light absorption capacity of $\mathrm{g}-\mathrm{C}_{3} \mathrm{~N}_{4}$, both of which increased the photocatalytic removal efficiency of NO. Under visible-light irradiation, the NO removal rate of CNT-12 was found to reach $33 \%$, which was maintained after five runs (Fig. 9c, d).

Liao et al. [74] also introduced nitrogen defects into the framework of $\mathrm{g}-\mathrm{C}_{3} \mathrm{~N}_{4}$ by heating the material in powder form in a hydrogen atmosphere; the NO removal rate on this catalyst was 2.6 times that of the original one because of its

(a)

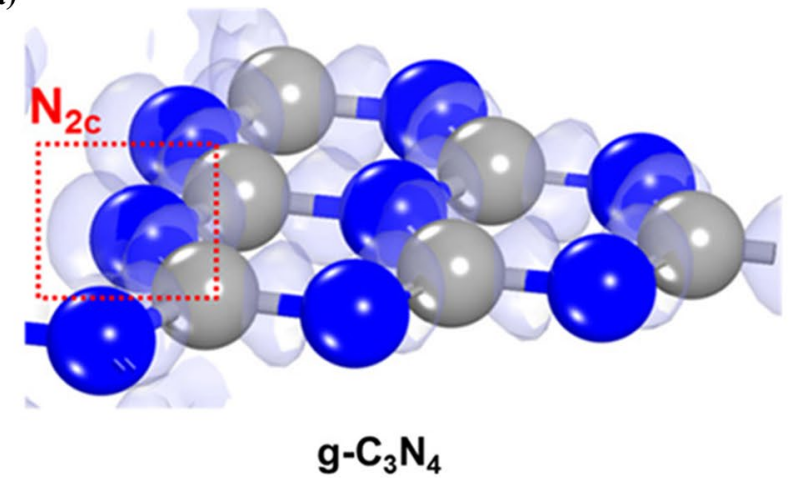

(c)

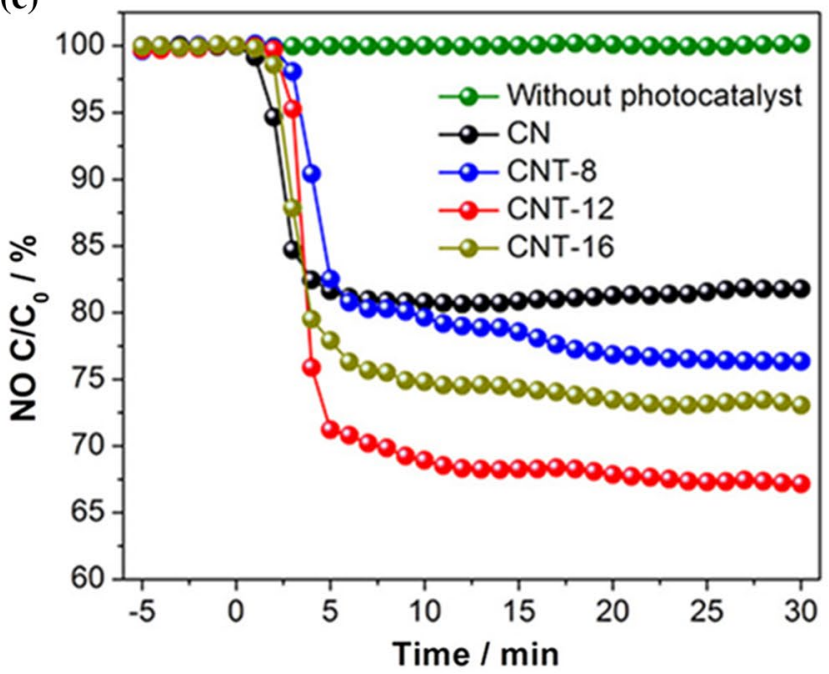

Fig. 9 Calculated electron density difference (EDD) diagrams of g- $\mathrm{C}_{3} \mathrm{~N}_{4}$ a and $\mathrm{N}_{2 \mathrm{c}}$-deficient $\mathrm{g}_{-} \mathrm{C}_{3} \mathrm{~N}_{4} \mathbf{b}$; visible-light photocatalytic activities of CN, CNT-8, CNT-12, and CNT-16 toward NO removal much narrower band gap, which can promote the separation of photoexcited charge carriers and generate active oxygen more efficiently under visible-light irradiation. In addition, Ma et al. [75] reported that the combination of metal oxides could improve the specific surface area of ${ }^{-}-\mathrm{C}_{3} \mathrm{~N}_{4}$ and promote the separation of photogenerated electrons and holes, and thus, improve its photocatalytic activity. They prepared $\mathrm{g}^{-} \mathrm{C}_{3} \mathrm{~N}_{4}-\mathrm{TiO}_{2}$ composites using commercial P25 and melamine as precursors through a simple calcination route and found the interface interaction between $\mathrm{g}_{-} \mathrm{C}_{3} \mathrm{~N}_{4}$ and $\mathrm{TiO}_{2}$ increased the separation efficiency of photogenerated electrons and holes and generated more active species. Tian et al. [76] also used a hybrid calcination method to build a g- $\mathrm{C}_{3} \mathrm{~N}_{4} / \mathrm{Bi}_{4} \mathrm{O}_{5} \mathrm{I}_{2} 2 \mathrm{D}-2 \mathrm{D}$ heterojunction nanosheet photocatalyst that showed an enhanced photocatalytic activity of NO removal (with the rate of $51 \%$ after 30 min of irradiation) compared with the original $\mathrm{g}-\mathrm{C}_{3} \mathrm{~N}_{4}$ and $\mathrm{Bi}_{4} \mathrm{O}_{5} \mathrm{I}_{2}$ under visible light $(\lambda \geq 420 \mathrm{~nm})$ because of the promoted separation and transfer of photogenerated electron-hole pairs. (b)

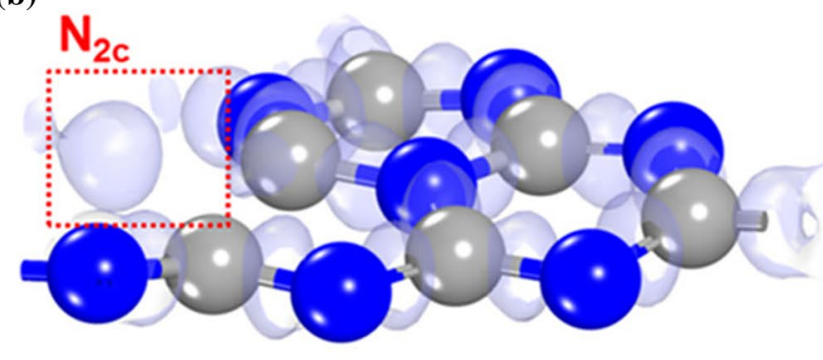

\section{$\mathrm{N}_{2 c}$-deficient g- $\mathrm{C}_{3} \mathrm{~N}_{4}$}

(d)

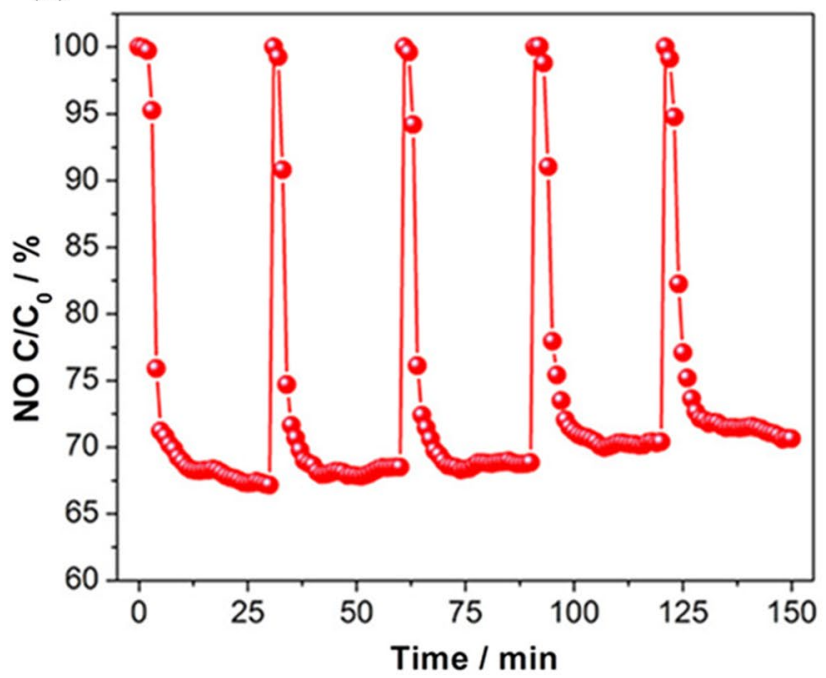

in air c; cycling of CNT-12 during NO removal d ( Reproduced with permission from Ref. [73]. Copyright 2019 American Chemical Society) 


\section{MOFs}

Extensive strategies have been devoted to enhancing the activities of traditional photocatalysts toward the oxidation of $\mathrm{NO}_{x}$, especially for photoexcitation in the visible-light spectral region, including the introduction of heteroatoms, the creation of vacancies (such as $\mathrm{O}$ vacancies and $\mathrm{N}$ vacancies) [77], metal plasmon resonance [78], and combination of dyes (PI-g- $\mathrm{C}_{3} \mathrm{~N}_{4}$ ) [79]. However, these catalysts still face many shortcomings, such as the small surface area, limited gas adsorption capacity, low catalytic activity, and easy inactivation. Furthermore, $\mathrm{NO}_{2}$, a chemical more toxic than $\mathrm{NO}$, can easily accumulate at the surface of these catalysts. The MOFs, formed by connecting inorganic metal oxygen clusters as nodes with organic ligands, usually have super large surface areas, and thus, possess high gas adsorption capacities. For example, Yang et al. [80, 81] found that the Manchester Framework Materials (MFM-520 and MFM$300(\mathrm{Al})$ ) exhibited a high adsorption capacity of $4.2 \mathrm{mmol} / \mathrm{g}$ $(298 \mathrm{~K}, 0.01 \mathrm{bar})$ and $14.1 \mathrm{mmol} / \mathrm{g}$, respectively, for $\mathrm{NO}_{2}$ uptake under environmental conditions. Moreover, MFM$300(\mathrm{Al})$ showed a highly selective removal of gas mixtures at low concentrations of $\mathrm{NO}_{2}(1-5000 \mathrm{ppm})$. Such superiority offered MOFs with promise for use in the photocatalytic oxidation of $\mathrm{NO}_{x}$ [82-86]. In 2015, Zhang et al. [30] synthesized the MOF-like material $\mathrm{Ag} @ \mathrm{NH}_{2}-\mathrm{MOP}(\mathrm{Ti})$ using the microwave-assisted method; that photocatalyst showed excellent photocatalytic activity for oxidizing $\mathrm{NO}$ gas, with two times higher activity than that of $\mathrm{N}$-doped $\mathrm{TiO}_{2}$. In 2018, Zhang et al. [87] further reported the use of the microwave method to produce a new photocatalyst, $\mathrm{GO} / \mathrm{NH}_{2}-\mathrm{MIL}-$ 125 , with high crystalline monodisperse $\mathrm{NH}_{2}-\mathrm{MIL}-125$ on the surface of graphene. The strong interaction between
MOFs and graphene not only enhances its visible-light absorption but also improves the separation efficiency of photogenerated electrons/holes; thus, the $\mathrm{NO}_{x}$ removal rate on this catalyst can reach $50 \%$ under visible-light irradiation $(\lambda \geq 420 \mathrm{~nm})$. In addition, Zhang et al. [88] found that the $\mathrm{Cu}$ species with mixed valence states in $\mathrm{NH}_{2}-\mathrm{UIO}-66$ constructed a new ligand-linker metal $\mathrm{Cu}$ charge transfer pathway (LMCT), allowing electrons to be transferred from the organic linker to the $\mathrm{Cu}$ center (Fig. 10a). This novel electron transfer pathway prolonged the life of photogenerated electrons under visible light, making the activity of this catalyst as high as $88 \%$ and inhibiting the production of $\mathrm{NO}_{2}$. In addition, these catalysts showed excellent stability (Fig. 10b).

\section{Photoelectrocatalysis Routes for Removing $\mathrm{NO}_{x}$}

Compared with the traditional $\mathrm{NO}_{x}$ treatment process, the $\mathrm{PC}$ route has received extensive attention in the field of environmental purification because of its strong oxidation ability, low cost, and environmental friendliness [89-91]. However, the difficult separation and rapid recombination of photogenerated holes and electrons lead to the low NO conversion rate, poor stability, and the production of more toxic $\mathrm{NO}_{2}$ sometimes, all of which restrict its applications for $\mathrm{NO}_{x}$ removal [92]. In 1972, Fujishima and Honda [93] coated $\mathrm{N}$-type semiconductor $\mathrm{TiO}_{2}$ onto the electrode and achieved good water decomposition ability under the synergistic action of an external voltage. Subsequently, photoelectrocatalysis attracted widespread attention [94] and has proved effective for the removal of organic pollutants [93],

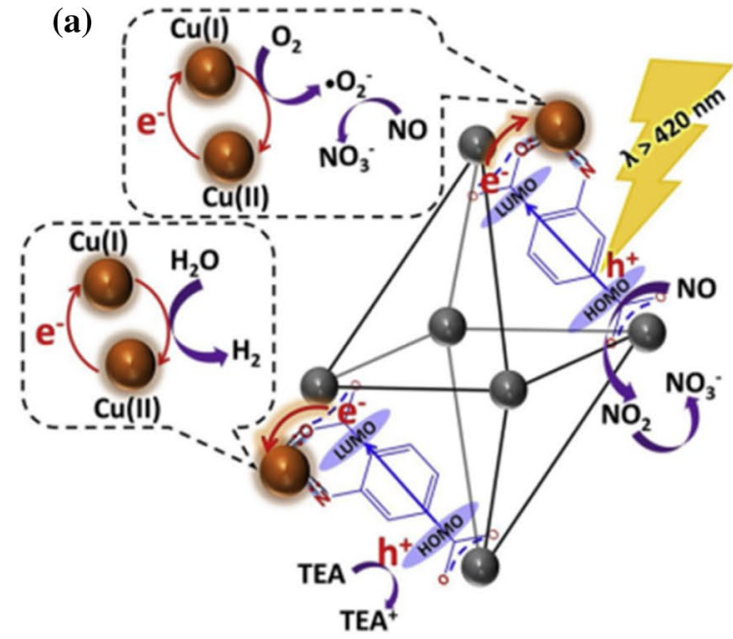

Fig. 10 a The proposed mechanism for photocatalytic NO oxidation in the gas phase of $\mathrm{CuNU} 7\left(\mathrm{Cu}-\mathrm{NH}_{2}-\mathrm{UiO}-66(\mathrm{Zr})\right)$; $\mathbf{b}$ the durability test of CuNU7 and $\mathrm{Cu}-\mathrm{NUO}\left(\mathrm{NH}_{2}-\mathrm{UIO}-66\right)$ for the photocatalytic (b)

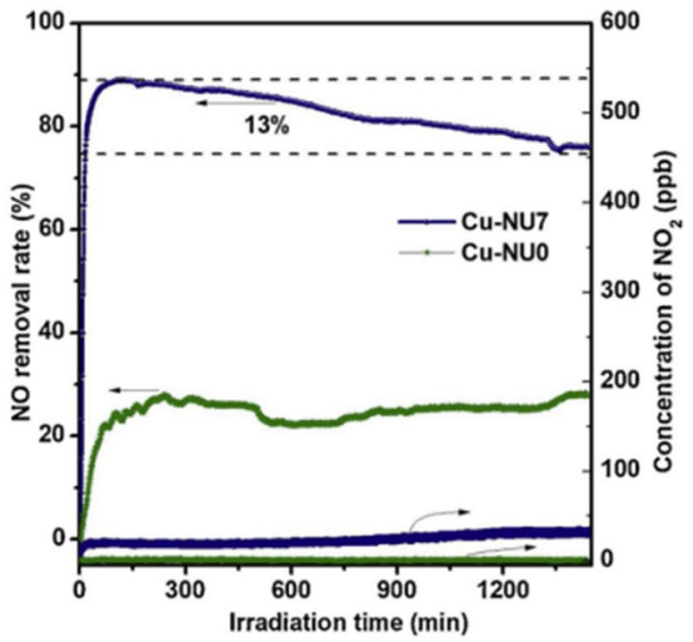

oxidation of NO ( Reproduced with permission from Ref. [88]. Copyright 2020 Elsevier) 
$\mathrm{CO}_{2}$ reduction $[95,96]$, and hydrogen or $\mathrm{H}_{2} \mathrm{O}_{2}$ production $[97,98]$. The introduction of bias voltage into the working system can further improve the performance of the photocatalytic reaction because of the efficient transfer of photogenerated carriers. However, the photocatalyst in powder form cannot be easily recovered and is easy to scatter and be inhaled by the human body, among other shortcomings. Coating photocatalysts onto the electrodes can overcome such shortcomings of powder catalysts [99]. Presently, most photoelectrocatalytic reactions have been conducted in the liquid phase; thus, introducing an appropriate conductive medium restricts its application to gas phase reaction. Zhang et al. [92, 100] established a reasonable photoelectrocatalytic system to serve as the gas-solid phase reactor for removing NO indoor gas. In 2019, Zhang et al. [92] reported an efficient PEC system for the treatment of $\mathrm{NO}_{x}$ through coating $\mathrm{TiO}_{2}$-nanoribbon/carbon-nanotube composites onto a stainless-steel mesh as the photoelectrode. In this system, carbon nanotubes enhanced the interaction between $\mathrm{TiO}_{2}$ and the stainless-steel skeleton, and thus, accelerated the transfer of photoelectrons to the auxiliary electrolytic cell for reduction reaction. Therefore, under ultraviolet irradiation, this PEC system can remove indoor NO gas (550 ppb) at a rate of more than $60 \%$, with a high selectivity to nitrate. As shown in Fig. 11a, the photogenerated electrons quickly separated from the holes and transferred to the counter electrode $(\mathrm{Pt})$, thereby allowing the photogenerated holes to oxidize NO molecules on the stainless-steel electrode under light irradiation at a small bias voltage. Such a PEC reactor was approved for use to effectively remove dry or wet NO; a trace amount of water can increase its efficiency [92]. However, the resistance at the interfaces between the catalysts and the substrate also affected the $\mathrm{NO}_{x}$ removal efficiency because the high resistance often required a large bias voltage to
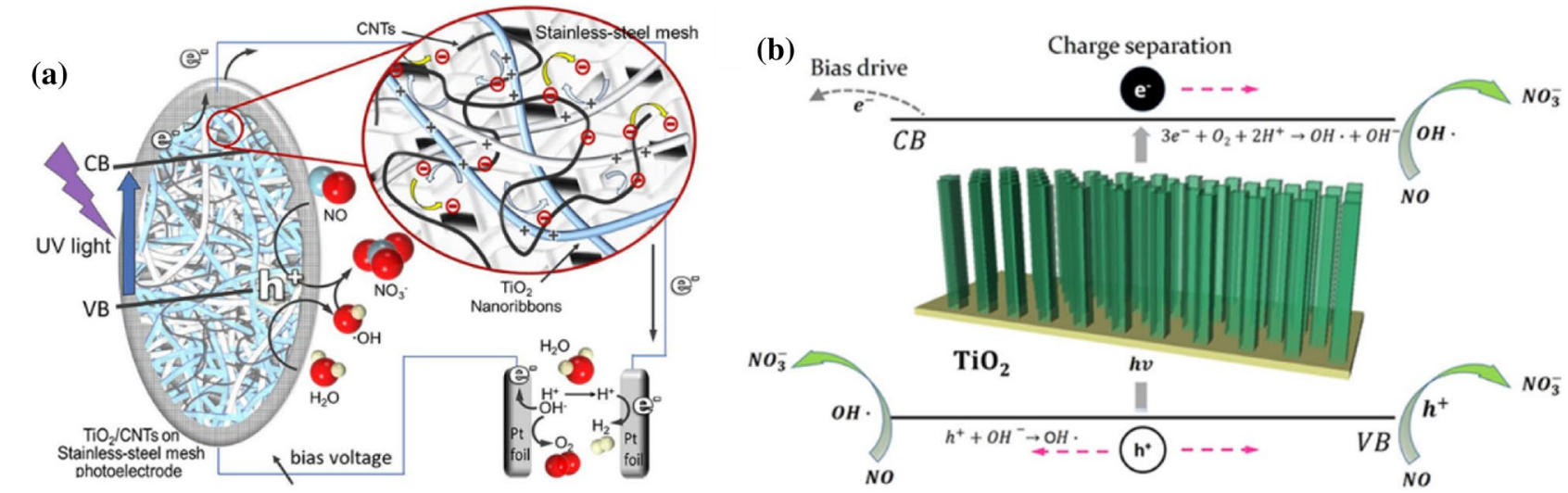

(c)

(d)
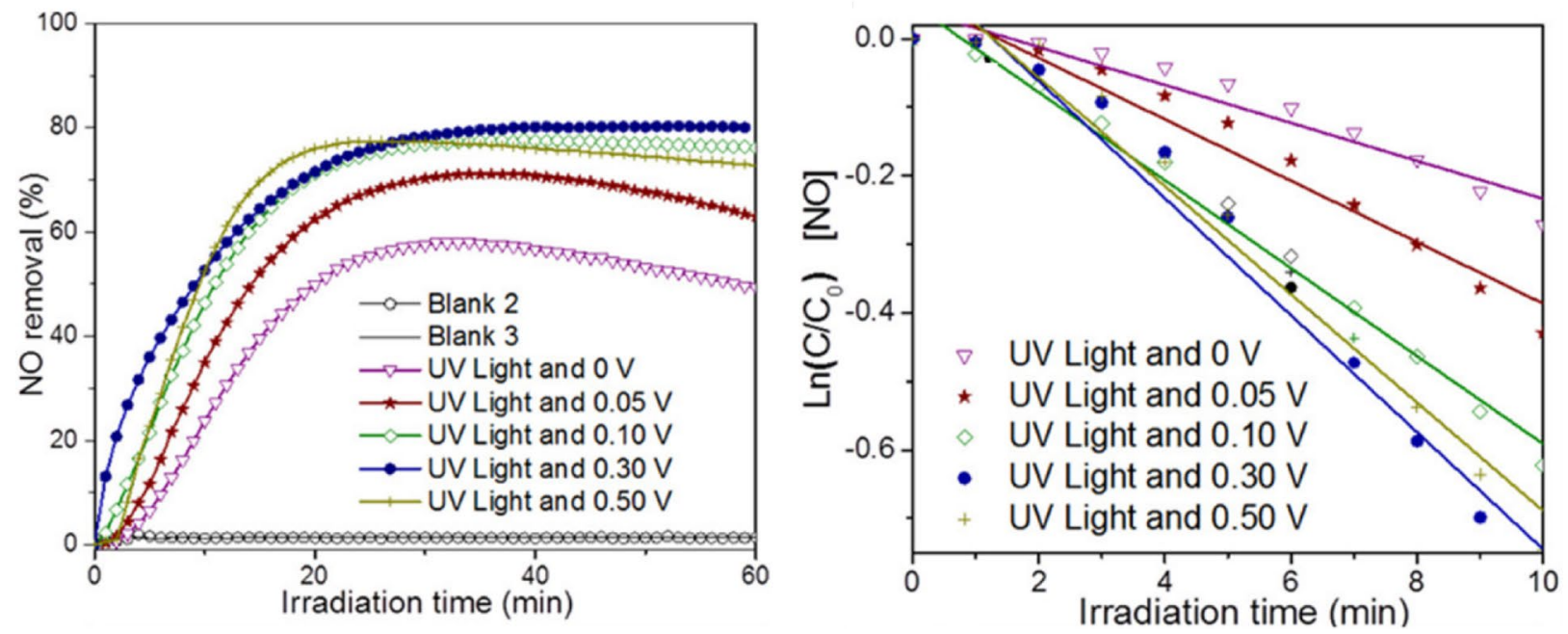

Fig. 11 Schematic illustration of the possible PEC mechanism of CT-25 for the oxidation of NO a ( Reproduced with permission from Ref. [92]. Copyright 2019 American Chemical Society); and the PC principle of $\mathrm{TiO}_{2}$ nano-arrays $\mathbf{b}$; $\mathbf{c}$ reaction profiles of the PEC NO oxidation on TF190 $\left(\mathrm{TiO}_{2}\right.$ is synthesized at $\left.190{ }^{\circ} \mathrm{C}\right)$ with different

bias voltages under UV light $(8 \times 4 \mathrm{~W}$ LED, $365 \mathrm{~nm})$ irradiation; d dependence of $\ln \left(C / C_{0}\right)$ on irradiation time (Reproduced with permission from Ref. [100]. Copyright 2020 American Chemical Society) 
overcome [101]. To solve the resistance problems, Zhang et al. [100] used FTO glass to act as microwave antennae and generated local superhot spots under microwave conditions (Fig. 11b). In that case, the titanium oxide nanoarray was grown in situ onto FTO glass, thus, solving the problem of insufficient interface contact and large resistance. At low bias voltage $(0.3 \mathrm{~V})$, the prepared photoanode had the optimal kinetic constants and the oxidation removal rate of $80 \%$ for NO (550 ppb) under illumination (Fig. 11c, d); this rate is much higher than that of the traditional PC process. Considering the symbiosis between photogenerated electrons and holes, the decoupling mechanism of the photogenerated carrier effect should be studied to solve the above key scientific problems. Therefore, our decoupling strategy is to introduce an external electric field to quickly transfer the photogenerated electrons to the counter electrode; this is the basis for the design of the gas-phase photoelectrocatalytic oxidation of NO. We found that the photoelectron transferability can be effectively regulated by adjusting the voltage of the external electric field. When the voltage was increased from 0 to $0.3 \mathrm{~V}$, the nitric oxide removal efficiency significantly increased from $58 \%$ to $83 \%$ (Fig. 11c). To identify the above promotion mechanism, our strategy was to eliminate the effect of $\mathrm{OH}$ by introducing a dry gas into the reaction chamber. Hydrogen peroxide was added to the electrolyte as an electron sacrifice agent to annihilate the electrons so that the photogenerated electrons can be transferred to the external circuit faster to increase the concentration of holes.

Higher hole concentration in the gas-phase photoelectric process is beneficial to the formation of $\mathrm{NO}_{3}{ }^{-}$(Fig. 12a), indicating that the hole concentration is crucial for the removal of nitric oxide because, with the increase in hole concentration, the rate constant of nitric oxide removal significantly increases (Fig. 12b). However, with the prolongation of reaction time, the production rate of $\mathrm{NO}_{2}$ gradually increased (Fig. 12c). To address this challenge, $\mathrm{H}_{2} \mathrm{O}$ was introduced into the gas-solid phase photoelectric $\mathrm{NO}$ oxidation process to demonstrate the catalytic effect of $\mathrm{H}_{2} \mathrm{O}$. The $\mathrm{NO}_{2}$ production rate was significantly reduced in $\mathrm{H}_{2} \mathrm{O}$ (Fig. 12c). This reduction occurred because the existence of $\mathrm{H}_{2} \mathrm{O}$ is conducive to the generation of $\mathrm{OH}$ so that the generation of $\mathrm{O}^{2-}$ is inhibited, thereby promoting the main $\mathrm{NO}_{3}{ }^{-}$reaction $[77,102]$. Furthermore, the removal efficiency of $\mathrm{NO}$ significantly improved in $\mathrm{H}_{2} \mathrm{O}$ compared with that in the absence of $\mathrm{H}_{2} \mathrm{O}$, indicating that there is a significant synergistic effect between the hydroxyl radical and hole concentration for inhibiting the generation of $\mathrm{NO}_{2}$ in the gas-solid phase photoelectric NO oxidation.

\section{Conclusion and Future Outlook}

With the continuous $\mathrm{NO}_{x}$ emissions from the activities of human beings, the development of methods to efficiently eliminate low-concentration $\mathrm{NO}_{x}$ is of growing importance. The photocatalytic oxidation of $\mathrm{NO}_{x}$ has been proved to be an effective method in recent years, and extensive efforts have been devoted to developing highly efficient photocatalysts. In this review, we described the mechanism of photocatalytic oxidation of $\mathrm{NO}_{x}$ and analyzed the key factors for developing highly active photocatalysts. The recent progress on the development of photocatalysts was summarized based
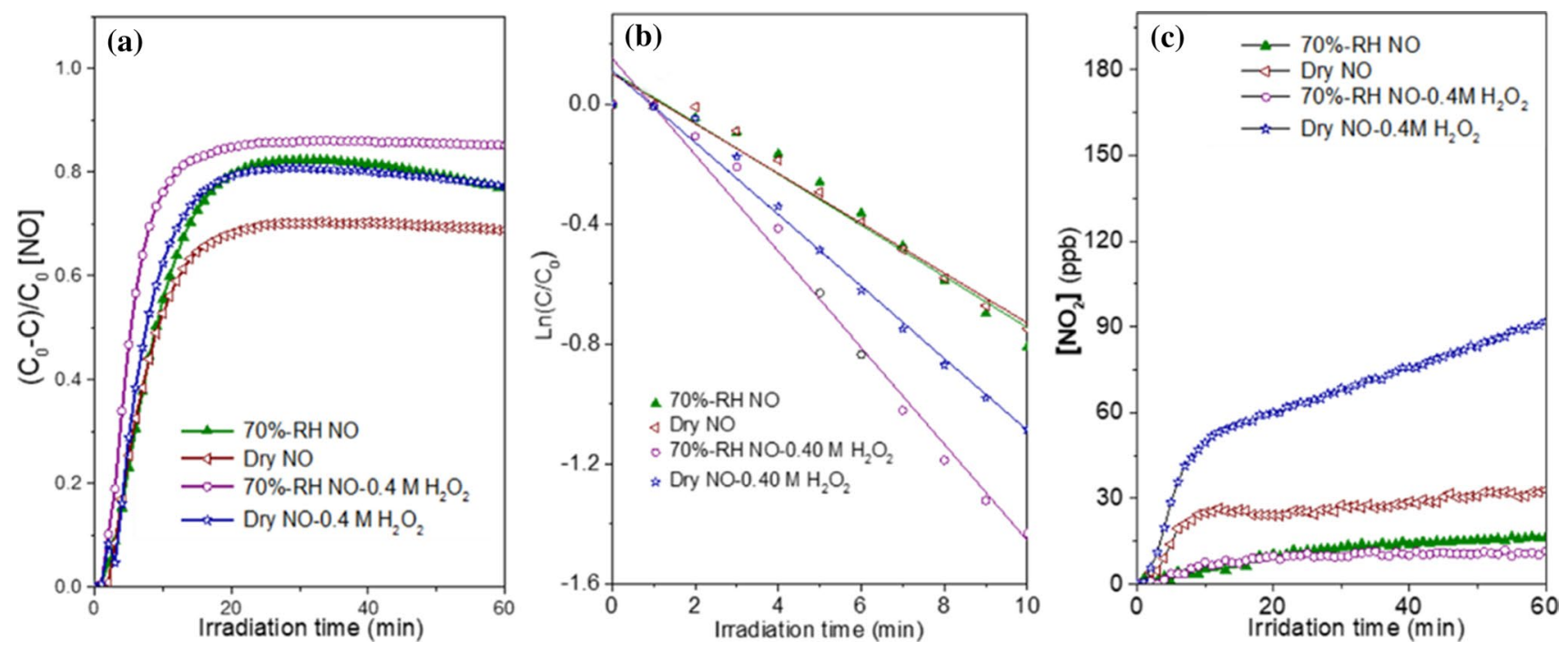

Fig. 12 a PEC oxidation of NO for TF190 under UV light irradiation with a $0.3 \mathrm{~V}$ bias voltage (70\% RH NO, dry NO, 70\% RH NO-0.40 M $\mathrm{H}_{2} \mathrm{O}_{2}$, dry NO-0.40 $\left.\mathrm{M} \mathrm{H}_{2} \mathrm{O}_{2}\right)$, b dependence of $\ln \left(C / C_{0}\right)$ on irradia- tion time, and $\mathbf{c}$ dependence of $\mathrm{NO}_{2}$ formation on irradiation time ( $\mathrm{R}$ eproduced with permission from Ref. [100]. Copyright 2020 American Chemical Society) 
on the categories of oxide inorganic semiconductors, $\mathrm{Bi}$ based inorganic semiconductors, the $\mathrm{g}_{-} \mathrm{C}_{3} \mathrm{~N}_{4}$ system, and MOFs. With the application of external voltage, the photoelectrocatalytic oxidation of $\mathrm{NO}_{x}$, in general, possesses higher $\mathrm{NO}_{x}$ removal efficiency than $\mathrm{PC}$ alone; recent progress in its development was also reviewed. The research progress of both photocatalytic and photoelectrocatalytic technology was reviewed, and the photocatalytic oxidation and photoelectrocatalytic oxidation mechanisms of $\mathrm{NO}_{x}$ were elucidated in detail. The modification and processing of inorganic photocatalysts, the design of new MOF photocatalysts, and the development of photoanode materials and photoelectrocatalytic reaction devices will become important research subjects in the future.

Currently, the photocatalytic oxidation of $\mathrm{NO}_{x}$ can only be driven by UV or visible light; longer wavelength light (infrared light or far-infrared light) cannot be used for driving the NO oxidation process. In the future, designing highly active longer-wavelength light-driving photocatalysts or active layers of photoanodes for oxidizing $\mathrm{NO}_{x}$ will be of great significance. In addition, achieving the synergistic degradation of $\mathrm{NO}_{x}, \mathrm{O}_{3}$, and VOCs in the case of complex atmospheric conditions is vital. This synergy will also play an important role in promoting the large-scale environmental application of indoor air pollution control and air purification filters in the future.

Acknowledgements This work was supported by the National Key Research and Development Program of China (No. 2020YFA0211004), and National Natural Science Foundation of China (Nos. 21876112, 21876113, 22022608), Shanghai Engineering Research Center of Green Energy Chemical Engineering and Shanghai Government (No. 18SG41), "111" Innovation and Talent Recruitment Base on Photochemical and Energy Materials (No. D18020).

Open Access This article is licensed under a Creative Commons Attribution 4.0 International License, which permits use, sharing, adaptation, distribution and reproduction in any medium or format, as long as you give appropriate credit to the original author(s) and the source, provide a link to the Creative Commons licence, and indicate if changes were made. The images or other third party material in this article are included in the article's Creative Commons licence, unless indicated otherwise in a credit line to the material. If material is not included in the article's Creative Commons licence and your intended use is not permitted by statutory regulation or exceeds the permitted use, you will need to obtain permission directly from the copyright holder. To view a copy of this licence, visit http://creativecommons.org/licenses/by/4.0/.

\section{References}

1. Lewis A, Edwards P (2016) Validate personal air-pollution sensors. Nature 535(7610):29-31

2. Ruiz-López MF, Martins-Costa MTC, Anglada JM et al (2019) A new mechanism of acid rain generation from HOSO at the air-water interface. J Am Chem Soc 141(42):16564-16568
3. Krajick K (2001) Acid rain: long-term data show lingering effects from acid rain. Science 292(5515):195-196

4. Glasson WA (1983) Reply to comment on "Effect of hydrocarbon and nitrogen oxide $\left(\mathrm{NO}_{x}\right)$ on photochemical smog formation under simulated transport conditions". Environ Sci Technol 17(1):62-63

5. Huebert BJ (1974) Computer modeling of photochemical smog formation. J Chem Educ 51(10):644

6. Ye X, Ma SG, Jiang X et al (2019) The adsorption of acidic gaseous pollutants on metal and nonmetallic surface studied by first-principles calculation: a review. Chin Chem Lett 30(12):2123-2131

7. Buysse CE, Kaulfus A, Nair U et al (2019) Relationships between particulate matter, ozone, and nitrogen oxides during urban smoke events in the western US. Environ Sci Technol 53(21):12519-12528

8. Gao HO, Niemeier DA (2008) Using functional data analysis of diurnal ozone and $\mathrm{NO}_{x}$ cycles to inform transportation emissions control. Transp Res Part D Transp Environ 13(4):221-238

9. Lelieveld J, Evans JS, Fnais M et al (2015) The contribution of outdoor air pollution sources to premature mortality on a global scale. Nature 525(7569):367-371

10. Zhao CN, Xu Z, Wu GC et al (2019) Emerging role of air pollution in autoimmune diseases. Autoimmun Rev 18(6):607-614

11. Schraufnagel DE, Balmes JR, Cowl CT et al (2019) Air pollution and noncommunicable diseases: a review by the forum of international respiratory societies' environmental committee, part 2: air pollution and organ systems. Chest 155(2):417-426

12. Rezaei F, Rownaghi AA, Monjezi S et al (2015) $\mathrm{SO}_{x} / \mathrm{NO}_{x}$ removal from flue gas streams by solid adsorbents: a review of current challenges and future directions. Energy Fuels 29(9):5467-5486

13. Blejchař T, Konvička J, von der Heide B et al (2018) High temperature modification of SNCR technology and its impact on $\mathrm{NO}_{x}$ removal process. EPJ Web Conf 180:02009

14. Damma D, Ettireddy P, Reddy B et al (2019) A review of low temperature $\mathrm{NH}_{3}$-SCR for removal of $\mathrm{NO}_{x}$. Catalysts 9(4):349

15. Schill L, Fehrmann R (2018) Strategies of coping with deactivation of $\mathrm{NH}_{3}-\mathrm{SCR}$ catalysts due to biomass firing. Catalysts 8(4): 135

16. Chen CM, Cao Y, Liu ST et al (2018) Review on the latest developments in modified vanadium-titanium-based SCR catalysts. Chin J Catal 39(8):1347-1365

17. Pu YJ, Xie XY, Jiang WJ et al (2020) Low-temperature selective catalytic reduction of $\mathrm{NO}_{x}$ with $\mathrm{NH}_{3}$ over zeolite catalysts: a review. Chin Chem Lett 31(10):2549-2555

18. Park JH, Ahn JW, Kim KH et al (2019) Historic and futuristic review of electron beam technology for the treatment of $\mathrm{SO}_{2}$ and $\mathrm{NO}_{x}$ in flue gas. Chem Eng J 355:351-366

19. Gholami F, Tomas M, Gholami Z et al (2020) Technologies for the nitrogen oxides reduction from flue gas: a review. Sci Total Environ 714:136712

20. Dong F, Zhao Z, Sun Y et al (2015) An advanced semimetalorganic Bi spheres- $g-\mathrm{C}_{3} \mathrm{~N}_{4}$ nanohybrid with SPR-enhanced visible-light photocatalytic performance for NO purification. Environ Sci Technol 49(20):12432-12440

21. Wang H, Sun YJ, Jiang GM et al (2018) Unraveling the mechanisms of visible light photocatalytic NO purification on earthabundant insulator-based core-shell heterojunctions. Environ Sci Technol 52(3):1479-1487

22. Ni ZL, Sun YJ, Zhang YX et al (2016) Fabrication, modification and application of $(\mathrm{BiO})_{2} \mathrm{CO}_{3}$-based photocatalysts: a review. Appl Surf Sci 365:314-335

23. Ibusuki T, Takeuchi K (1994) Removal of low concentration nitrogen oxides through photoassisted heterogeneous catalysis. J Mol Catal 88(1):93-102 
24. Wang KH, Tsai HH, Hsieh YH (1998) A study of photocatalytic degradation of trichloroethylene in vapor phase on $\mathrm{TiO}_{2}$ photocatalyst. Chemosphere 36(13):2763-2773

25. Yang JS, Liao WP, Wu JJ (2013) Morphology and interfacial energetics controls for hierarchical anatase/rutile $\mathrm{TiO}_{2}$ nanostructured array for efficient photoelectrochemical water splitting. ACS Appl Mater Interfaces 5(15):7425-7431

26. Huy TH, Bui DP, Kang F et al (2019) $\mathrm{SnO}_{2} / \mathrm{TiO}_{2}$ nanotube heterojunction: the first investigation of $\mathrm{NO}$ degradation by visible light-driven photocatalysis. Chemosphere 215:323-332

27. Sun ML, Li JY, Dong F (2020) Structure control methods of Bi based photocatalytic materials and research progress on their application in environmental energy field. J Huazhong Agri Uni 39(5):17-25 ((in Chinese))

28. Zhu S, Lu L, Zhao Z et al (2017) Mesoporous Ni-doped $\delta$ - $\mathrm{Bi}_{2} \mathrm{O}_{3}$ microspheres for enhanced solar-driven photocatalysis: a combined experimental and theoretical investigation. J Phys Chem C 121(17):9394-9401

29. Wang X, Maeda K, Thomas A et al (2009) A metal-free polymeric photocatalyst for hydrogen production from water under visible light. Nat Mater 8(1):76-80

30. Zhu W, Liu PJ, Xiao SN et al (2015) Microwave-assisted synthesis of Ag-doped MOFs-like organotitanium polymer with high activity in visible-light driven photocatalytic NO oxidization. Appl Catal B Environ 172-173:46-51

31. Gong XQ, Selloni A (2005) Reactivity of anatase $\mathrm{TiO}_{2}$ nanoparticles: the role of the minority (001) surface. J Phys Chem B 109(42):19560-19562

32. Selloni A (2008) Crystal growth-anatase shows its reactive side. Nat Mater 7(8):613-615

33. Wu BH, Guo CY, Zheng NF et al (2008) Nonaqueous production of nanostructured anatase with high-energy facets. J Am Chem Soc 130(51):17563-17567

34. Yang HG, Liu G, Qiao SZ et al (2009) Solvothermal synthesis and photoreactivity of anatase $\mathrm{TiO} 2$ nanosheets with dominant 001 facets. J Am Chem Soc 131(11):4078-4083

35. Li GX, Fang K, Ou Y et al (2021) Surface study of the reconstructed anatase $\mathrm{TiO}_{2}(001)$ surface. Prog Nat Sci Mater Int 31(1):1-13

36. Yang HG, Sun CH, Qiao SZ et al (2008) Anatase $\mathrm{TiO}_{2}$ single crystals with a large percentage of reactive facets. Nature 453(7195):638-641

37. Han X, Kuang Q, Jin M et al (2009) Synthesis of titania nanosheets with a high percentage of exposed (001) facets and related photocatalytic properties. J Am Chem Soc 131(9):3152-3153

38. Chen L, Yang SD, Zhang Q et al (2021) Rational design of $\{00$ 1 \}-faceted $\mathrm{TiO}_{2}$ nanosheet arrays/graphene foam with superior charge transfer interfaces for efficient photocatalytic degradation of toxic pollutants. Sep Purif Technol 265:118444

39. Duan YY, Luo JM, Zhou SC et al (2018) $\mathrm{TiO}_{2}$-supported Ag nanoclusters with enhanced visible light activity for the photocatalytic removal of NO. Appl Catal B Environ 234:206-212

40. Martinez-Oviedo A, Ray SK, Joshi B et al (2020) Enhancement of $\mathrm{NO}_{x}$ photo-oxidation by $\mathrm{Fe}$ - and $\mathrm{Cu}$-doped blue $\mathrm{TiO}_{2}$. Environ Sci Pollut Res 27(21):26702-26713

41. Xiao SN, Zhang DQ, Pan DL et al (2019) A chloroplast structured photocatalyst enabled by microwave synthesis. Nat Commun 10:1570

42. He Y, Li JY, Li KL et al (2020) Bi quantum dots implanted 2D C-doped $\mathrm{BiOCl}$ nanosheets: enhanced visible light photocatalysis efficiency and reaction pathway. Chin J Catal 41(9):1430-1438

43. Lei B, Cui W, Sheng JP et al (2020) Synergistic effects of crystal structure and oxygen vacancy on $\mathrm{Bi}_{2} \mathrm{O}_{3}$ polymorphs: intermediates activation, photocatalytic reaction efficiency, and conversion pathway. Sci Bull 65(6):467-476

44. Dong F, Wang Z, Li Y et al (2014) Immobilization of polymeric g- $\mathrm{C}_{3} \mathrm{~N}_{4}$ on structured ceramic foam for efficient visible light photocatalytic air purification with real indoor illumination. Environ Sci Technol 48(17):10345-10353

45. He WJ, Sun YJ, Jiang GM et al (2018) Activation of amorphous $\mathrm{Bi}_{2} \mathrm{WO}_{6}$ with synchronous $\mathrm{Bi}$ metal and $\mathrm{Bi}_{2} \mathrm{O}_{3}$ coupling: photocatalysis mechanism and reaction pathway. Appl Catal B: Environ 232:340-347

46. Hu J, Chen D, Mo Z et al (2019) Z-scheme 2D/2D heterojunction of black phosphorus/monolayer $\mathrm{Bi}_{2} \mathrm{WO}_{6}$ nanosheets with enhanced photocatalytic activities. Angew Chem Int Ed Engl 58(7):2073-2077

47. Cheng HF, Huang BB, Dai Y (2014) Engineering BiOX (X=Cl, $\mathrm{Br}$, I) nanostructures for highly efficient photocatalytic applications. Nanoscale 6(4):2009-2026

48. Li J, Yu Y, Zhang LZ (2014) Bismuth oxyhalide nanomaterials: layered structures meet photocatalysis. Nanoscale 6(15):8473-8488

49. Ye LQ, Su YR, Jin XL et al (2014) Recent advances in BiOX $(\mathrm{X}=\mathrm{Cl}, \mathrm{Br}$ and $\mathrm{I})$ photocatalysts: synthesis, modification, facet effects and mechanisms. Environ Sci: Nano 1(2):90-112

50. Zhang HJ, Liu L, Zhou Z (2012) Towards better photocatalysts: first-principles studies of the alloying effects on the photocatalytic activities of bismuth oxyhalides under visible light. Phys Chem Chem Phys 14(3):1286-1292

51. Zhang HJ, Liu L, Zhou Z (2012) First-principles studies on facet-dependent photocatalytic properties of bismuth oxyhalides (BiOXs). RSC Adv 2(24):9224-9229

52. Wang L, Lv D, Dong F et al (2019) Boosting visible-light-driven photo-oxidation of $\mathrm{BiOCl}$ by promoted charge separation via vacancy engineering. ACS Sustain Chem Eng 7(3):3010-3017

53. Lv Y, Zhu YY, Zhu YF (2013) Enhanced photocatalytic performance for the $\mathrm{BiPO}_{4-x}$ nanorod induced by surface oxygen vacancy. J Phys Chem C 117(36):18520-18528

54. Liu YF, Lv Y, Zhu YY et al (2014) Fluorine mediated photocatalytic activity of $\mathrm{BiPO}_{4}$. Appl Catal B: Environ 147:851-857

55. Li JY, Dong XA, Sun YJ et al (2018) Facet-dependent interfacial charge separation and transfer in plasmonic photocatalysts. Appl Catal B Environ 226:269-277

56. Wang H, Yuan XZ, Wu Y et al (2017) Plasmonic Bi nanoparticles and $\mathrm{BiOCl}$ sheets as cocatalyst deposited on perovskitetype $\mathrm{ZnSn}(\mathrm{OH})_{6}$ microparticle with facet-oriented polyhedron for improved visible-light-driven photocatalysis. Appl Catal B: Environ 209:543-553

57. Fang WJ, Jiang Z, Yu L et al (2017) Novel dodecahedron $\mathrm{BiVO}_{4}$ : $\mathrm{YVO}_{4}$ solid solution with enhanced charge separation on adjacent exposed facets for highly efficient overall water splitting. J Catal 352:155-159

58. Jiang GM, Li XW, Lan MN et al (2017) Monodisperse bismuth nanoparticles decorated graphitic carbon nitride: enhanced visible-light-response photocatalytic NO removal and reaction pathway. Appl Catal B Environ 205:532-540

59. Li JR, Zhang WD, Ran MX et al (2019) Synergistic integration of Bi metal and phosphate defects on hexagonal and monoclinic $\mathrm{BiPO}_{4}$ : enhanced photocatalysis and reaction mechanism. Appl Catal B Environ 243:313-321

60. Greaves C, Blower SK (1988) Structural relationships between $\mathrm{Bi}_{2} \mathrm{O}_{2} \mathrm{CO}_{3}$ and $\beta-\mathrm{Bi}_{2} \mathrm{O}_{3}$. Mater Res Bull 23(7):1001-1008

61. Lu YF, Huang Y, Zhang YF et al (2019) Effects of $\mathrm{H}_{2} \mathrm{O}_{2}$ generation over visible light-responsive $\mathrm{Bi} / \mathrm{Bi}_{2} \mathrm{O}_{2-x} \mathrm{CO}_{3}$ nanosheets on their photocatalytic $\mathrm{NO}_{x}$ removal performance. Chem Eng J 363:374-382 
62. Xiong T, Cen WL, Zhang YX et al (2016) Bridging the g- $\mathrm{C}_{3} \mathrm{~N}_{4}$ interlayers for enhanced photocatalysis. ACS Catal 6(4):2462-2472

63. Wang D, Saleh NB, Sun W et al (2019) Next-generation multifunctional carbon-metal nanohybrids for energy and environmental applications. Environ Sci Technol 53(13):7265-7287

64. Li K, He Y, Chen P et al (2020) Theoretical design and experimental investigation on highly selective Pd particles decorated $\mathrm{C}_{3} \mathrm{~N}_{4}$ for safe photocatalytic NO purification. J Hazard Mater 392:122357

65. Chen ZF, Lu SC, Wu QL et al (2018) Salt-assisted synthesis of $3 \mathrm{D}$ open porous $\mathrm{g}-\mathrm{C}_{3} \mathrm{~N}_{4}$ decorated with cyano groups for photocatalytic hydrogen evolution. Nanoscale 10(6):3008-3013

66. He F, Chen G, Zhou Y et al (2015) The facile synthesis

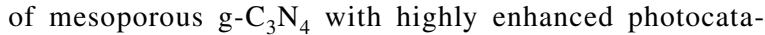
lytic $\mathrm{H}_{2}$ evolution performance. Chem Commun (Camb) 51(90):16244-16246

67. Raziq F, Qu Y, Humayun $\mathrm{M}$ et al (2017) Synthesis of $\mathrm{SnO}_{2} / \mathrm{B}-\mathrm{P}$ codoped g- $\mathrm{C}_{3} \mathrm{~N}_{4}$ nanocomposites as efficient cocatalyst-free visible-light photocatalysts for $\mathrm{CO}_{2}$ conversion and pollutant degradation. Appl Catal B Environ 201:486-494

68. Fu YS, Huang T, Jia BQ et al (2017) Reduction of nitrophenols to aminophenols under concerted catalysis by $\mathrm{Au} / \mathrm{g}-\mathrm{C}_{3} \mathrm{~N}_{4}$ contact system. Appl Catal B Environ 202:430-437

69. Zhou M, Dong GH, Yu FK et al (2019) The deep oxidation of $\mathrm{NO}$ was realized by $\mathrm{Sr}$ multi-site doped $\mathrm{g}_{-} \mathrm{C}_{3} \mathrm{~N}_{4}$ via photocatalytic method. Appl Catal B Environ 256:117825

70. Zhang ZZ, Xu MK, Ho W et al (2016) Simultaneous excitation of $\mathrm{PdCl}_{2}$ hybrid mesoporous g- $\mathrm{C}_{3} \mathrm{~N}_{4}$ molecular/solid-state photocatalysts for enhancing the visible-light-induced oxidative removal of nitrogen oxides. Appl Catal B Environ 184:174-181

71. Yang Y, Zhang Q, Zhang R et al (2018) Compressible and recyclable monolithic $\mathrm{g}_{-} \mathrm{C}_{3} \mathrm{~N}_{4} /$ melamine sponge: a facile ultrasoniccoating approach and enhanced visible-light photocatalytic activity. Front Chem 6:156

72. Liu YW, Xiao C, Li Z et al (2016) Vacancy engineering for tuning electron and phonon structures of two-dimensional materials. Adv Energy Mater 6(23): 1600436

73. Wang Z, Huang Y, Chen M et al (2019) Roles of N-vacancies over porous $\mathrm{g}_{-} \mathrm{C}_{3} \mathrm{~N}_{4}$ microtubes during photocatalytic $\mathrm{NO}_{x}$ removal. ACS Appl Mater Interfaces 11(11):10651-10662

74. Liao JZ, Cui W, Li JY et al (2020) Nitrogen defect structure and $\mathrm{NO}+$ intermediate promoted photocatalytic $\mathrm{NO}$ removal on $\mathrm{H}_{2}$ treated g- $\mathrm{C}_{3} \mathrm{~N}_{4}$. Chem Eng J 379:122282

75. Ma JZ, Wang CX, He H (2016) Enhanced photocatalytic oxidation of $\mathrm{NO}$ over g- $\mathrm{C}_{3} \mathrm{~N}_{4}-\mathrm{TiO}_{2}$ under UV and visible light. Appl Catal B Environ 184:28-34

76. Tian N, Zhang YH, Liu CY et al (2016) G-C $\mathrm{C}_{3} \mathrm{~N}_{4} / \mathrm{Bi}_{4} \mathrm{O}_{5} \mathrm{I}_{2} 2 \mathrm{D}-2 \mathrm{D}$ heterojunctional nanosheets with enhanced visible-light photocatalytic activity. RSC Adv 6(13):10895-10903

77. Shang H, Li M, Li H et al (2019) Oxygen vacancies promoted the selective photocatalytic removal of $\mathrm{NO}$ with blue $\mathrm{TiO}_{2}$ via simultaneous molecular oxygen activation and photogenerated hole annihilation. Environ Sci Technol 53(11):6444-6453

78. Dong F, Li QY, Sun YJ et al (2014) Noble metal-like behavior of plasmonic $\mathrm{Bi}$ particles as a cocatalyst deposited on $(\mathrm{BiO})_{2} \mathrm{CO}_{3}$ microspheres for efficient visible light photocatalysis. ACS Catal 4(12):4341-4350

79. Hu JD, Chen DY, Li NJ et al (2018) 3D aerogel of graphitic carbon nitride modified with perylene imide and graphene oxide for highly efficient nitric oxide removal under visible light. Small 14(19): 1800416

80. Han X, Godfrey HGW, Briggs L et al (2018) Reversible adsorption of nitrogen dioxide within a robust porous metal-organic framework. Nat Mater 17(8):691-696
81. Li J, Han X, Zhang X et al (2019) Capture of nitrogen dioxide and conversion to nitric acid in a porous metal-organic framework. Nat Chem 11(12):1085-1090

82. Zeng L, Guo XY, He C et al (2016) Metal-organic frameworks: versatile materials for heterogeneous photocatalysis. ACS Catal 6(11):7935-7947

83. Zhang T, Lin W (2014) Metal-organic frameworks for artificial photosynthesis and photocatalysis. Chem Soc Rev 43(16):5982-5993

84. Li SL, Xu Q (2013) Metal-organic frameworks as platforms for clean energy. Energy Environ Sci 6(6):1656-1683

85. Stock N, Biswas S (2012) Synthesis of metal-organic frameworks (MOFs): routes to various MOF topologies, morphologies, and composites. Chem Rev 112(2):933-969

86. Zhou HCJ, Kitagawa S (2014) Metal-organic frameworks (MOFs). Chem Soc Rev 43(16):5415-5418

87. Li XR, Le ZY, Chen XL et al (2018) Graphene oxide enhanced amine-functionalized titanium metal organic framework for visiblelight-driven photocatalytic oxidation of gaseous pollutants. Appl Catal B Environ 236:501-508

88. Chen XL, Cai Y, Liang R et al (2020) $\mathrm{NH}_{2}-\mathrm{UiO}-66(\mathrm{Zr})$ with fast electron transfer routes for breaking down nitric oxide via photocatalysis. Appl Catal B: Environ 267:118687

89. Li GS, Zhang DQ, Yu JC (2008) Ordered mesoporous $\mathrm{BiVO}_{4}$ through nanocasting: a superior visible light-driven photocatalyst. Chem Mater 20(12):3983-3992

90. Huang Y, Ho W, Lee S et al (2008) Effect of carbon doping on the mesoporous structure of nanocrystalline titanium dioxide and its solar-light-driven photocatalytic degradation of $\mathrm{NO}_{x}$. Langmuir 24(7):3510-3516

91. Cui W, Li J, Dong F et al (2017) Highly efficient performance and conversion pathway of photocatalytic NO oxidation on SrO-Clusters@Amorphous carbon nitride. Environ Sci Technol 51(18):10682-10690

92. Xiao SN, Wan Z, Zhou JC et al (2019) Gas-phase photoelectrocatalysis for breaking down nitric oxide. Environ Sci Technol 53(12):7145-7154

93. Fujishima A, Honda K (1972) Electrochemical photolysis of water at a semiconductor electrode. Nature 238(5358):37-38

94. Ma TY, Dai S, Jaroniec M et al (2014) Metal-organic framework derived hybrid $\mathrm{Co}_{3} \mathrm{O}_{4}$-carbon porous nanowire arrays as reversible oxygen evolution electrodes. J Am Chem Soc 136(39):13925-13931

95. Sun JY, Guo YP, Wang Y et al (2018) $\mathrm{H}_{2} \mathrm{O}_{2}$ assisted photoelectrocatalytic degradation of diclofenac sodium at g- $\mathrm{C}_{3} \mathrm{~N}_{4} / \mathrm{BiVO}_{4}$ photoanode under visible light irradiation. Chem Eng J 332:312-320

96. Qi Y, Xu Q, Wang Y et al (2016) $\mathrm{CO}_{2}$-induced phase engineering: protocol for enhanced photoelectrocatalytic performance of $2 \mathrm{D}$ $\mathrm{MoS}_{2}$ nanosheets. ACS Nano 10(2):2903-2909

97. Xie S, Zhang Q, Liu G et al (2016) Photocatalytic and photoelectrocatalytic reduction of $\mathrm{CO}_{2}$ using heterogeneous catalysts with controlled nanostructures. Chem Commun (Camb) 52(1):35-59

98. Daghrir R, Drogui P, El Khakani MA (2013) Photoelectrocatalytic oxidation of chlortetracycline using $\mathrm{Ti} / \mathrm{TiO}_{2}$ photo-anode with simultaneous $\mathrm{H}_{2} \mathrm{O}_{2}$ production. Electrochim Acta 87:18-31

99. Leng WH, Zhu WC, Ni J et al (2006) Photoelectrocatalytic destruction of organics using $\mathrm{TiO}_{2}$ as photoanode with simultaneous production of $\mathrm{H}_{2} \mathrm{O}_{2}$ at the cathode. Appl Catal A Gen 300(1):24-35

100. Dai WR, Tao Y, Zou HJ et al (2020) Gas-phase photoelectrocatalytic oxidation of $\mathrm{NO}$ via $\mathrm{TiO}_{2}$ nanorod array/FTO photoanodes. Environ Sci Technol 54(9):5902-5912

101. Hoet PH, Brüske-Hohlfeld I, Salata OV (2004) Nanoparticlesknown and unknown health risks. J Nanobiotechnology 2(1):12

102. Li H, Shang H, Cao X et al (2018) Oxygen vacancies mediated complete visible light $\mathrm{NO}$ oxidation via side-on bridging superoxide radicals. Environ Sci Technol 52(15):8659-8665 


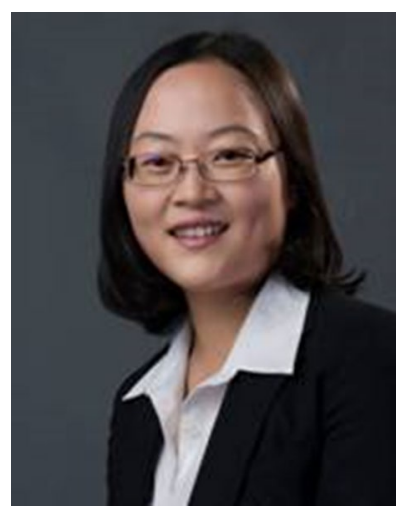

Dieqing Zhang received her $\mathrm{PhD}$ degree in 2010 at the Chinese University of Hong Kong, China. Now she is a professor and Master Tutor of Shanghai Normal University and International Joint Laboratory of Resource Chemistry. Her actual interests is air pollution control. She has won the first prize of Shanghai Natural Science Award (5/5) and has been selected to support talent programs such as Shanghai Top Young Talents Program,
Shuguang Scholar, Young Science and Technology Starlight, and Pujiang Scholar. She presided over the National Science Foundation for Excellent Young People in 2020. 